Botany Research Journal 12 (1-4): 1-30, 2019

ISSN: $1995-4751$

(C) Medwell Journals, 2019

\title{
Traditional System of Medicine and Nutritional Supplementation: Use vs. Regulation
}

\author{
Abdul Kader Mohiuddin \\ Secretary and Treasurer, Dr. M. Nasirullah Memorial Trust, Tejgaon, \\ 1215 Dhaka, Bangladesh
}

\begin{abstract}
Food is the major source for serving the nutritional needs but with growing modernization some traditional ways are being given up. Affluence of working population with changing lifestyles and reducing affordability of sick care in terms of time and money involved are some of the forces that are presently driving people towards thinking about their wellness. There has been increased global interest in traditional medicine. Efforts to monitor and regulate traditional herbal medicine are underway. Ayurveda, the traditional Indian medicine, remains the most ancient yet living traditions. Although, India has been successful in promoting its therapies with more research and science-based approach, it still needs more extensive research and evidence base. Increased side effects, lack of curative treatment for several chronic diseases, high cost of new drugs, microbial resistance and emerging, diseases are some reasons for renewed public interest in complementary and alternative medicines. Numerous nutraceutical combinations have entered the international market through exploration of ethnopharmacological claims made by different traditional practices. This review gives an overview of the Ayurvedic system of medicine and its role in translational medicine in order to overcome malnutrition and related disorders. Many of the scientific and regulatory challenges that exist in research on the safety, quality and efficacy of dietary supplements are common to all countries as the marketplace for them becomes increasingly global.
\end{abstract}

Key words: Dietary supplements, food supplements, supplement science, scientific challenges, regulatory challenges, natural health product, complementary medicine, traditional medicines, National Institutes of Health, Office of Dietary Supplements

\section{INTRODUCTION}

India is known for its traditional medicinal systems Ayurveda, Siddha and Unani. Medical systems are found mentioned even in the ancient Vedas and other scriptures. The Ayurvedic concept appeared and developed between 2500 and $500 \mathrm{BC}$ in India. The fundamental challenge in any discussion about the regulation of dietary supplements is that there is no global consensus on how the category of products known variously as dietary supplements, Natural Health Products (NHPs), complementary medicines or food supplements in different countries is defined. For example, a product considered to be a dietary supplement and regulated as a food in the USA in another jurisdiction may be considered a food supplement or a therapeutic good (complementary medicine) or a therapeutic good (prescription medicine) or potentially even a controlled substance. The situation is even more complicated when countries like China or India that have an existing regulatory framework for traditional medicine or phytomedicine that includes crude botanicals are considered. To add further to the confusion, many regulatory frameworks are changing. Another challenge is that while all regulatory scientists want to protect consumers from harm, ensure that consumers have the ability to make informed choices about the products they use and do the right thing, the scientific challenges and regulatory systems that have arisen to deal with them vary greatly from country to country. Even in countries with similar cultures, legal systems and levels of economic development, regulations applying to dietary supplements vary considerably. Some of these differences are explored below using examples from Australia, Canada and the USA, all English-speaking countries with largely similar cultures and legal systems to illustrate this point. The discussion of other countries with similar legal systems such as the United Kingdom, New Zealand and South Africa or other nations in the Americas, Europe, Africa and Asia, often with different cultures, legal systems and levels of economic development is left for others with greater expertise and experience. A final challenge is that "dietary supplement" health products are often very emotive and polarizing topics, evoking a diverse range of opinions and viewpoints. While some observers may contend that these products should be considered in a similar fashion to conventional drugs and foods, others believe that a more tailored approach is necessary, since, there is often a traditional or historical evidence base and products often contain multiple ingredients. Increasingly, this situation has become even more complex because of 


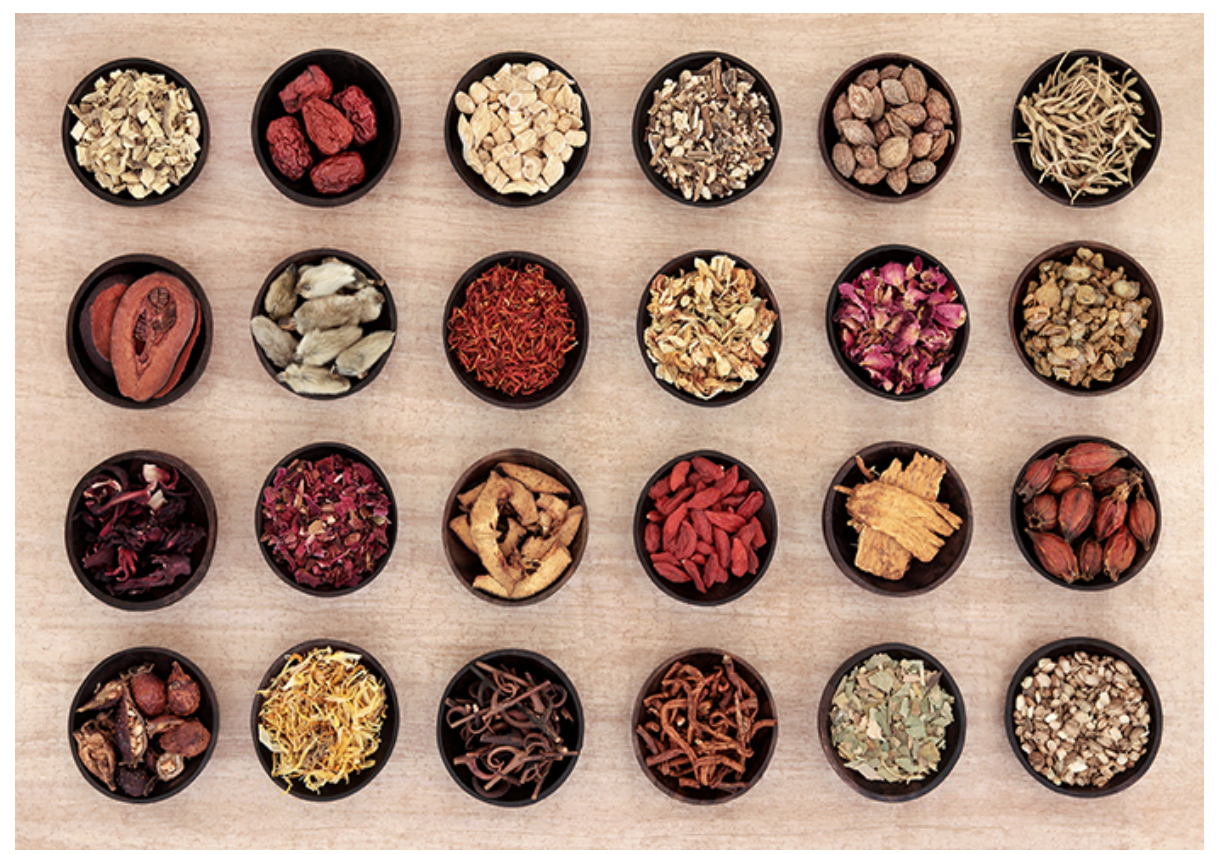

Fig. 1: Dietary supplements

the lucrative nature of the global dietary supplement sector, increased involvement of a growing industry sector producing them and the introduction of many new and innovative products onto the market. A detailed discussion of the politics of the subject is outside the scope of this paper. However, it must be recognized that politics may play both a positive and negative role in shaping both regulatory frameworks and research agendas. Irrespective of the reader's point of view, this context is important in any discussion of dietary supplement products (Fig.1).

Dietary supplements: Herbal supplements are regulated by the FDA but not as drugs or as foods. They fall under a category called dietary supplements. Manufacturers don't have to seek FDA approval before selling dietary supplements. Companies can claim that products address a nutrient deficiency, support health or are linked to body functions if they have supporting research and they include a disclaimer that the FDA hasn't evaluated the claim. The FDA is responsible for monitoring dietary supplements that are on the market. If the FDA finds a product to be unsafe, it can take action against the manufacturer or distributor or both and may issue a warning or require that the product be removed from the market. These regulations provide assurance that: Herbal supplements meet certain quality standards. The FDA can intervene to remove dangerous products from the market (Herbal supplements: What to know before you buy. MAYO CLINIC Nov. 08, 2017).
Planning and development of new herbal preparation: Analysis of active substances in the selected plant raw materials and quality control prescribed by Pharmacopoeia or another relevant document are performed. Then, the quality control of semifinal product is conducted. In the case of capsules, the analysis of the active substance in dry extract is performed and also the analysis of other parameters that define its quality and that is defined by Pharmacopoeia monographs or summarized in an internal specification or a certificate. Afterwards, the preparation formulation is conducted (formulation of teas or herbal drops, herbal creams, capsules, etc.). In addition to the main plant raw materials, secondary raw materials are selected which will synergistically facilitate the functioning of the dominant plant drugs and auxiliary pharmaceutical raw materials are selected. Auxiliary raw materials are used as the basis for semi-solid galenic forms (creams, ointments and gels) and capsule fillers (Djordjevic SM. From Medicinal Plant Raw Material to Herbal Remedies. In: IntechOpen Limited DOI: 10.5772/66618) (Fig. 2).

Importance of research on dietary supplements: Internationally, herbal products are regulated under different classifications, some of which are: complimentary medicines; natural health products; prescription medicines; over the counter medicines; supplements; traditional herbal medicines, etc. Until relatively recently, there was limited scientific research on dietary supplements and so, little was known about them (White, 1941). However, the prevalence of supplement 


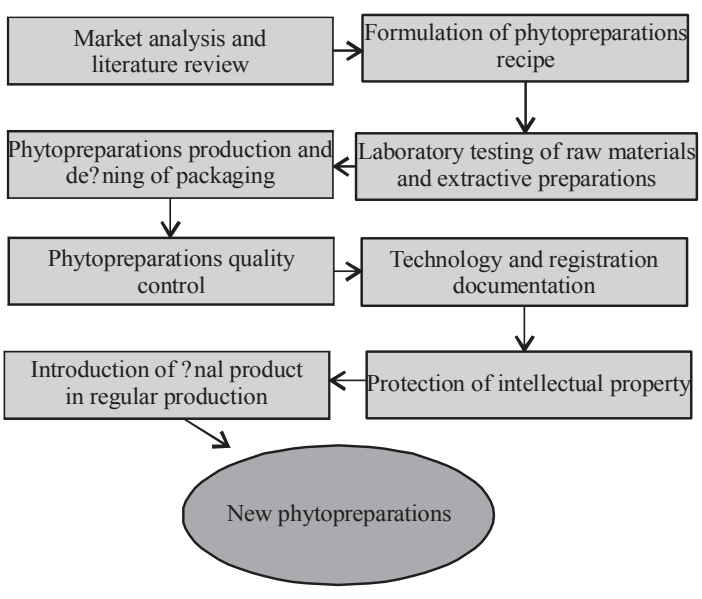

Fig. 2: Planning and development of new herbal preparation

use has increased dramatically over the past 20 years (Kantor et al., 2016) and they have become a matter of consumer interest (Marik and Flemmer, 2012; Manson et al., 2016). At the same time, the application of state-of-the art scientific methods to explore issues involving dietary supplements has advanced rapidly. The other invited articles in this special issue illustrate progress in our understanding of supplement science as it applies to several nutrients including vitamin $\mathrm{D}$, iron, omega-3 fatty acids and iodine. Progress on botanicals and other non-nutrient ingredients (e.g., glucosamine, Methyl-Sulfonyl-Methane (MSM), coenzyme Q10) has been more challenging (Balentine et al., 2015). There is no global consensus in terminology for the category of products known variously as dietary supplements, NHPs and food supplements in different countries and while we recognize this limitation for the purpose of this study the term dietary supplement will be used to refer to such products as nutritional supplements, herbal medicines and traditional medicines. This study summarizes some of the scientific challenges in supplement research and some resources that may be useful in studying them. Most of the scientific challenges in supplement science are ubiquitous and global, so, it is vital for scientists to collaborate across nations to help meet them without duplicating effort. A case study is provided by the work of the NIH Office of Dietary Supplements (ODS) which has been pursuing this goal, since, 2000. Some freely available resources and tools that ODS has developed for advancing health-related scientific knowledge on supplements are presented. The supplement marketplace is increasingly international, making collaboration between regulators essential, since, national decisions have international implications. Since, products are consumed world-wide, calls for global quality standards are emerging. The remainder of the article focuses on regulatory challenges involving dietary supplements and perspectives on how the regulatory systems in a number of different countries deal with them. Key resources for learning more about these approaches are provided.

\section{Exhibit 1: international regulatory overview of herbal supplements \\ India: Herbal drugs are regulated under the Drug and Cosmetic Act (D and C) 1940 and Rules 1945 in India where regulatory provisions for Ayurveda, Unani, Siddha medicine are clearly laid down.}

Malaysia: Herbal products in Malaysia fall under the category of regulated products. Any marketer intending to place the herbal products in the market require to register the product first. The applicant is required to be registered with the Malaysia Registrar of Business or Suruhanjaya Syarikat Malaysia under two classifications.

Philippines: The Bureau of Food and Drugs (BFAD) who are the regulators in the country, mandate registration of the traditionally used herbal products before manufacture, import or market. The extent of control of BFAD includes the brand names of the traditional herbal products as well and their prior clearance is required, before filing for product registration.

Nigeria: Nigeria, the trade of herbal products is regulated by National Agency for Food and Drug Administration and Control (NAFDAC) who has classified these products as "Herbal Medicines and Related Products." Premarketing registration of herbal medicines and related products is mandatory in Nigeria. No advertisement can be made as a cure for any disease conditions listed in "Schedule 1" to the Food and Drug Act 1990.

Australia: Complementary medicines which do not require medical supervision are permitted and have to be entered on the Australian Register for Therapeutic Goods (ARTG) before marketing. The low-risk medicines require to be listed while the medicines for comparatively higher risk therapeutic conditions require registration on the ARTG. Only evidence-based claims which are entered on the ARTG are allowed.

United States: As per FDA, the drug must be marketed under an approved New Drug Application (NDA). FDA regulates the dietary supplements under the Dietary Supplement Health and Education Act of 1994. The claims need to comply with the regulatory guidelines issued by the FDA. The manufacturing of dietary supplements should be done as per the current GMP for dietary supplements.

Canada: Complete data on product composition, standardization, stability, microbial and chemical contaminant testing methods and tolerance limits, safety and efficacy along with ingredient characterization, quantification by assay or by input needs to be submitted 
to Natural Health Product Directorate (NHPD). The authority mandates that NHPs must comply with the contaminant limits and must be manufactured as per the GMP norms.

European Union: The European Medicine Agency have laid down two ways of registration of herbal medicinal products: a full marketing authorization by submission of a dossier which provides the information on quality, safety and efficacy of the medicinal products including the physicochemical, biological or microbial tests and pharmacological, toxicological and clinical trials data; under directive 2001/83/EC. For traditional herbal medicinal products which do not require medical supervision and where evidence of long traditional of use of medicinal products exists and adequate scientific literature to demonstrate a well-established medicinal use cannot be provided, a simplified procedure under directive 2004/24/EC exists. Current status of herbal product: Regulatory overview. J Pharm Bioallied Sci. 2015;7(4):293.

Areas of scientific consensus about supplement science: Although, there is broad consensus on the need for advances in science to make progress, opinions vary on the best paths to take and on priority areas for consideration.

Quality: The supply of ingredients used in supplements has outpaced the availability of methods and trained personnel to analyze them. For example in 1994 when the Dietary Supplement Health and Education Act (DSHEA) first became law in the USA about 600 US manufacturers of supplements were producing an estimated 4000 products. By 2000, more than 29,000 supplement products were on the US market but few documented analytical methods or Reference Materials (RM) were available for these products. This growth in the market has also been evident internationally. For example, there are anecdotal reports that over 100,000 product license applications have been approved in Canada, since, the Natural Health Products Regulations came into force in 2005 . The need for improving quality continues today, since, now there are estimated to be more than 85,000 supplement products in the US marketplace and concerns about ingredient misidentification, safety concerns and quality assurance/control problems continue to be important for the industry and the public (Mudge et al., 2016; Orhan et al., 2016). The first step in characterizing supplement products is generally identifying the ingredients. Plant identification is a particular challenge. Even when easily identified whole plants or plant parts are used unless the chain of custody is tight and the exact manufacturing process is known and well characterized, the quality of extracts and blends such as those found in many botanical products is difficult to ascertain. Reliable analytical methods to characterize the bioactive components in supplements are helpful but even for the nutrients in supplements, specific analytical chemistry methods must be often developed (Dwyer et al., 2007). The bio-actives in supplements differ from those in foods in their matrices in that the forms, combinations and doses in which they are consumed and the circumstances under which they are used are likely to differ. Analytical techniques for other bio-actives in supplements are further complicated because the active compound (s) are often unknown and even when they are known, validated analytical methods may not exist for determining their content. Reference materials are often unavailable to compare results between different laboratories for research purposes and to monitor data and supplement quality.

Safety: Manufacturers are prohibited from marketing supplement products that are unsafe or contain unsafe ingredients. This includes assuring that safe upper levels of intake for nutrients or maximum dosages for other constituents are not exceeded and ensuring that toxic contaminants are absent. Improved accuracy and precision of the nutrient measurements, bioactive marker compounds for other ingredients, natural toxins, toxic elements and/or pesticides in dietary supplement ingredients and finished products will be helpful to regulatory agencies.

Efficacy: Demonstration of efficacy typically depends on a number of research approaches ranging from basic in-vitro research on the mechanisms of action to animal and human studies. For example, in the past, large and expensive clinical trials using poorly characterized herbal supplement products for which the mechanisms of action were not understood were performed, leading to results that were inconclusive and irreproducible (Swanson, 2002; Wolsko et al., 2005; Gagnier et al., 2006). These experiences led publishers and funders to demand better product characterization and funders to demand more mechanistic evidence of bioactivity. Once mechanistic plausibility is established, animal and small phase 1 and 2 trials should precede the launch of large phase 3 studies of efficacy. More and better clinical studies of the safety and efficacy of dietary supplements on "hard" health outcomes are also sorely needed. Health outcomes such as changes in validated surrogate markers for performance, functions, morbidity and mortality from diseases or conditions are required rather than changes in biochemical measures in blood with unvalidated surrogate markers. The question of the use of evidence from traditional forms of health and healing such as Traditional Chinese Medicine (TCM) makes the question of efficacy often more complex. This is briefly explored in the regulatory section below. 
Exhibit 2. Parameters of quality control for herbal preparations

Herbal drugs:

- Definition: the name of the herbal drugs and content of active substances

- Characters: appearance, taste, odor, solubility

- Identification: macroscopic and microscopic examination, TLC

- Tests: water, loss on drying, total ash, foreign matter, insoluble matter, extractable matter, swelling index, microbiological purity, bitterness value, broken drug

- Assay: essential oils, tannins, declared active substances (GC, LC, UV-VIS)

Herbal drug preparations dry extract (extractum siccum)

- Definition: standardized dry extract prepared from..., content of active substances

- Production: method of extraction and solvents

- Characters: appearance

- Identification: TLC

- Tests: loss on drying, total ash, microbiological purity

- $\quad$ Assay: declared active substances (LC)

\section{Liquid extract (Extractum fluidum)}

- Definition: liquid extract produced from ... and content of active substances

- Production: method of extraction and solvents

- Characters: appearance, taste, odor

- Identification: TLC

- Tests: ethanol, methanol and 2-propanol, loss on drying, microbiological purity

- Assay: declared active substances (LC, UV-VIS)

\section{Tincture (Tinctura):}

- Definition: tincture produced from... and content of active substances

- Production: method of extraction and solvents

- Characters: appearance, taste, odor

- Identification: TLC

- Tests: ethanol, methanol and 2-propanol, dry residue, microbiological purity

- Assay: declared active substances (LC, UV-VIS)

\section{Essential oil (Aetheroleum):}

- Definition: essential oil obtained by ... and content of dominant components

- Production: method of extraction and solvents

- Characters: appearance, odor, solubility

- Identification: TLC and chromato Graphic profile (GC and GC-MS)
- Tests: relative density, refractive index, optical rotation, chromatographic profile (European Pharmacopoeia 8)

Translation of the science: Widespread consensus exists on the need to translate the scientific evidence on supplements into appropriate recommendations, regulations and policies that ensure the public health. Population-based prevalence estimates of supplement use are needed to estimate total exposures to nutrients or other bioactives that can be related to health outcomes (Dwyer et al., 2017). Monitoring is especially, important when supplementation is used as a public health strategy to fill nutrient gaps in deficient populations. It is also needed in other countries such as the USA where use of certain supplements is high and where substantial proportions of total intakes of nutrients such as vitamin D and calcium come from supplements, especially among older adults (Ahluwalia et al., 2016).

Exhibit 3: Parameters of quality control of phyto-preparation

Phyto-preparations

Mono-component tea and tea mixture

Parameters of quality control:

- Identification

- Appearance

- Verification of components, declared mass ratio of components

- Verification of package weight

- Microbiological purity

- Liquid herbal preparations

(Liquid extracts, tinctures and mixtures of extracts or tinctures), herbal drops, solutions, syrups:

- Identification

- Appearance

- Loss on drying

- Content of ethanol

- Relative density

- Refractive index

- Verification of package weight

- Qualitative and quantitative analysis

- Microbiological safety and/or complete health safety control

Semi-solid forms (herbal gels, cream and unguent):

- Identification

- Appearance

- Verification of package weight

- $\mathrm{pH}$ value

- Microbiological safety and/or complete health safety control 


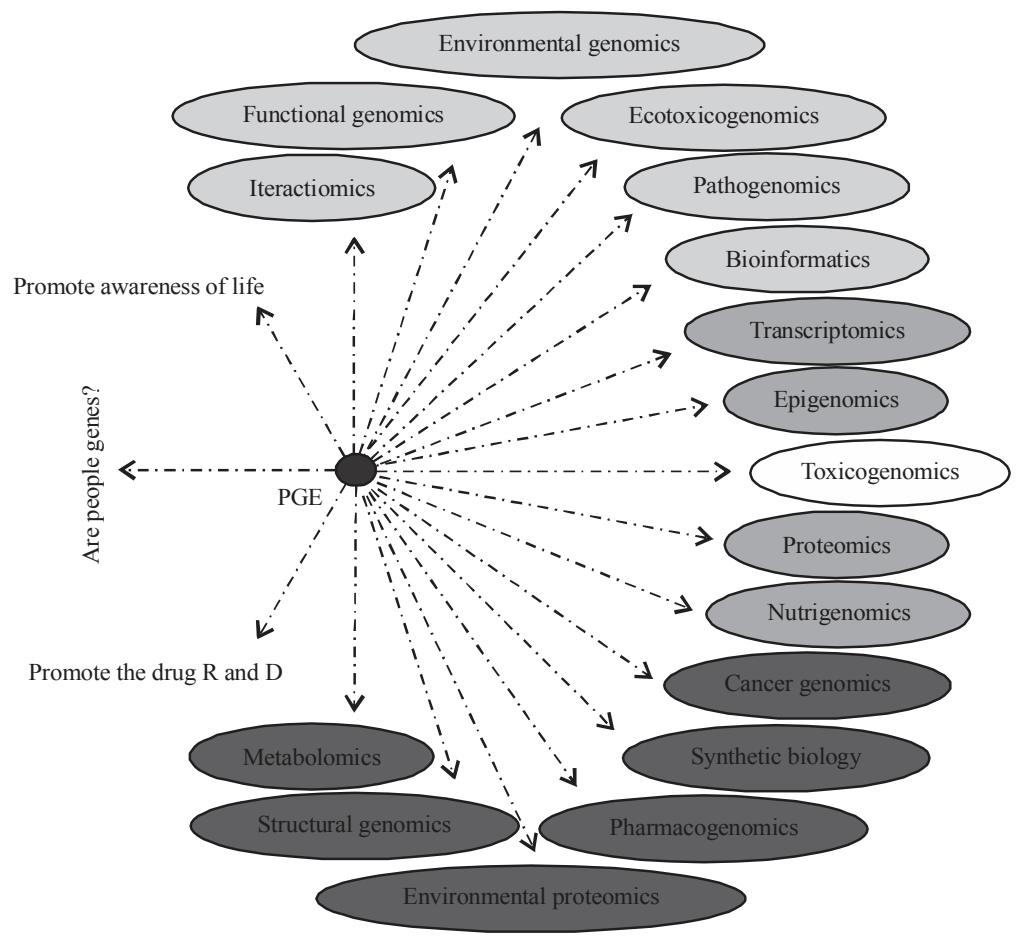

Fig. 3: "Postgenomic" era (PGE) and the associated new disciplines of study

Solid-dosage forms (capsules, tablets, etc.):

- Identification

- Appearance

- Declared mass of single-dose preparations

- Disintegration

- Qualitative and quantitative analysis of the declared active components

- Microbiological safety and/or complete health safety control (European Pharmacopoeia 8)

Challenges and resources: regulatory perspectives: As with other categories of regulated goods such as foods and drugs, the development of regulations is a balancing act where many different factors need to be taken into account. Notable among these are ensuring that products are of high quality and safe that any claims made are truthful and not misleading and that there is reasonable and appropriate access to the marketplace. All regulatory scientists want to both protect consumers from harm and support them in making informed choices about the products they include or as importantly do not include in their healthcare options. Appropriate regulatory oversight of this category is very challenging and requires that scientists and regulators work together as the former director general of the (Chan et al., 2013). This study provides a concise overview of how these regulations have been developed and common themes as well as challenges faced in a global market.
"Postgenomic" era (PGE) and the associated new disciplines of study: Firstly, in this "postgenomic" era, the screening of herbal ingredients should be accelerated. Due to the development of related disciplines in the "postgenomic" era, the pace of drug discovery from herbal medicine is likely to be hastened and become more efficient than ever with a resultant higher success rate. Unlike synthetic drugs, drugs derived from herbal medicine are developed by isolating and identifying the active chemical entities in the crude herbal extract, rather than by going through processes of drug design and synthesis. Although many aids and tools for advanced drug design are now available and the in vivo properties of a drug can also be predicted using quantum mechanics and statistical mechanics, the complexity of biological systems often defies some of the basic assumptions of rational drug design. As such it is impossible to estimate all drug-related parameters in an accurate manner during the "pregenomic" era. It is estimated that a single herbal preparation may contain more than 100 active compounds and their bioactivities and/or drug-like properties are difficult to be accurately identified and evaluated by conventional pharmacological methods or drug screening approaches (Zhou et al. New Perspectives on How to Discover Drugs from Herbal Medicines: CAM's Outstanding Contribution to Modern World Health Organization, Margaret Chan, MD urged Therapeutics. Evid Based Complement Alternat Med. 2013; 2013:627375) (Fig. 3). 
Definition of "dietary supplements": Although, the definition of dietary supplement within a specific jurisdiction such as the USA is quite precise (Taylor, 2004; Anonymous, 2017a-d), a fundamental challenge to any discussion on regulation is that there is no global consensus on either what falls within this category or even what the category is called. Intuitively many equate a dietary supplement in the USA with a NHP in Canada or a traditional herbal medicine in the European Union or a complementary medicine in Australia but this is not the case. For example while melatonin is regulated in the USA as a dietary supplement and in Canada as a NHP in Australia it is considered as a prescription medicine (Anonymous, 2017a-d; Ventola, 2010). Dehydroepiandrosterone (DHEA) is readily available as a dietary supplement in the US while in many other jurisdictions it is regulated as a controlled substance and is subject to significant regulatory oversight (Anonymous, 2017a-d).

This situation is even more complicated when one considers that in addition to dietary supplements such as vitamins and minerals, many of these products come from traditional systems of health and healing such as TCM in
China and Ayurvedic/Unani/Siddha medicine in India. For this reason, we must differentiate between the manner in which nations regulate the practice of medicine and the manner in which they regulate marketed products used in medical practice or as foods. In the US, the practice of medicine is regulated by the states while marketed food and drug products in interstate commerce are regulated by the Federal government. Approaches and regulatory frameworks in many parts of the world, notably in Asia, reflect this fact with terminology and categories developed accordingly (Anonymous, 2010).

To assist in development of its Traditional Medicine Strategy 2014-2023, the World Health Organization refers to this category as Traditional and Complementary Medicines (T\&CM) (World Health Organization, 2013). Although, this classification does have significant limitations, it recognizes the fact that definitions for this category vary significantly globally. Descriptions of specific national/regional definitions and categories can be found through the list of resources in Table 1.

While it would be easy just to consider that the substance itself is the defining factor in determining whether or not a product is a dietary supplement, this is

Table 1: Useful Global Resources on dietary supplement regulatory issues and definitions

\begin{tabular}{lll}
\hline Names & URL & Comments \\
\hline USA & www.fda.gov/food/dietarysupplements/ & $\begin{array}{l}\text { Details on regulations, policies and guidelines dealing with dietary } \\
\text { sDApplements }\end{array}$ \\
$\begin{array}{l}\text { administration dietary } \\
\text { supplements }\end{array}$ & &
\end{tabular}

Australia

Therapeutic Goods www.tga.gov.au/complementary-medicines Administration (TGA)

Food standards Australia www.foodstandards.gov.au/Pages/default.aspx and New Zealand

Canada

Health Canada

EU European Union

iament and Co European Food Safety Authority (EFSA)

\section{China}

China Food and Drugs

Administration (CFDA)

China-special administrative region of Hong Kong Health Ministry-Chinese medicine division Japan

www.canada.ca/en/health-canada/services/ drugshealth-products/natural-non-prescription. html

www.canada.ca/en/health-canada/services/ foodnutrition/legislation-guidelines/guidance documents/category-specific-guidance-temporary marketing-authorization-supplemented-food.htm

il ec.europa.eu/health/human-use/herbalmedicines_en www.efsa.europa.eu eng.sfda.gov.cn/WS03/CL0755/

www.cmd.gov.hk/html/eng/important_info/ regulation.html www.mhlw.go.jp/english/topics/foodsafety/fhc/ 02.html

Singapore

Health sciences authority www.hsa.gov.sg/content/hsa/en.html
Dails on the traditional herbal medicine directive re: member state

Details of existing complementary medicine regulations, policies and guidelines

Details on food standards, policies and guidelines

Details on the existing NHP regulations, policies and guidelines as well as work underway with regards to a comprehensive approach to self care products

Information on supplemented food category Provides details and links to regulation of foods and food supplements

Information on health food regulations including 'blue hat' process. (Note: English translation was not available)

Information on policies and regulation related to Chinese proprietary medicines

Information on policies, regulation and guidelines related to health products and Chinese proprietary medicines. As a member state, resource to access work on regulatory harmonization of products within Association of South East Asian Nations (ASEAN) 
Bot. Res. J., 12 (1-4): 1-30, 2019

Table 1: Continue

\begin{tabular}{|c|c|c|}
\hline Names & URL & Comments \\
\hline \multicolumn{3}{|l|}{ New Zealand } \\
\hline Medsafe & $\begin{array}{l}\text { www.medsafe.govt.nz/regulatory/Dietary } \\
\text { Supplements/Regulation.asp }\end{array}$ & $\begin{array}{l}\text { Provides information related to regulation, policies and guidelines } \\
\text { dealing with dietary supplements }\end{array}$ \\
\hline \multicolumn{3}{|l|}{ India } \\
\hline $\begin{array}{l}\text { Food Safety and Standards } \\
\text { Authority of India (FSSAI) }\end{array}$ & fssai.gov.in/home & $\begin{array}{l}\text { Government direction, standards and regulation of health supplements } \\
\text { and nutraceuticals. New regulations published in November } 2016 \\
\text { take effect in January } 2018 \text {. Health supplements are intended to } \\
\text { supplement the diet of healthy individuals over } 5 \text { year and levels of } \\
\text { nutrients should not exceed RDA amounts }\end{array}$ \\
\hline $\begin{array}{l}\text { Ministry of Ayurveda, } \\
\text { Yoga, Unani, Siddha and } \\
\text { Homeopathy (AYUSH) }\end{array}$ & ayush.gov.in & $\begin{array}{l}\text { Policies, guidelines and regulations dealing with Indian traditional } \\
\text { medicines }\end{array}$ \\
\hline WHO & who.int/medicines/areas/traditional/en/ & $\begin{array}{l}\text { Provides links to on-going work by the WHO including the Traditional } \\
\text { Medicine Strategy 2014-2023, the International Regulation on the } \\
\text { Cooperation of Herbal Medicines and various technical guidelines }\end{array}$ \\
\hline $\begin{array}{l}\text { World self medication } \\
\text { industry }\end{array}$ & www.wsmi.org & $\begin{array}{l}\text { Industry association website providing details on international } \\
\text { approaches to over-the-counter medicines including dietary } \\
\text { supplements }\end{array}$ \\
\hline $\begin{array}{l}\text { International Alliance of } \\
\text { Dietary/Food Supplement } \\
\text { Associations (IADSA) }\end{array}$ & www.iadsa.org & $\begin{array}{l}\text { Industry association website providing details on international } \\
\text { approaches to dietary supplements }\end{array}$ \\
\hline
\end{tabular}

not the case. Two other important factors considered are the claim that the product is making and how the product is supplied or recommended (intended use). In many jurisdictions such as the USA, Canada and Australia, dietary supplements are considered suitable for selfselection without the need for the intervention of a practitioner or prescription. Here, the claims that can be made are limited to minor conditions and to the support of health and wellness depending on the jurisdiction (Anonymous, 2017a-d; Anonymous, 2004). In other jurisdictions, notably those where a traditional form of health and healing is recognized, traditional and complementary medicine products are often prescribed and in some cases supply is limited only to trained practitioners.

\section{Exhibit 4 An overview of the regulatory options for regulating practitioners of traditional/complementary medicine \\ Area of regulation \\ Regulatory options \\ Education and training:}

- Type of qualification: university education, specific training for practitioners of traditional/ complementary medicine and for conventional health care practitioners

- Educational setting: schools, colleges or universities

- Specify standards in terms of length of training vs. content of core curriculum

- Shared biomedical curriculum vs. alternative curriculum

- Private/professional associations accredit courses vs. independent accreditation (by registering body or government)

- Training component of conventional medical training aimed at familiarization vs. integration

\section{Licensing and registration:}

- Individual registration vs. associations of practitioners register (and all members automatically registered)

- Automatic registration with accredited qualification vs. licensing exam vs. both

- Recognition of prior non-accredited training or experience vs. licensing exam

- Lifetime membership vs. re-licensing (associated with continuing medical education)

- Joint or dual licensing of practitioners of traditional/complementary medicine and conventional medical practitioners practicing traditional/complementary medicine vs. no additional licensing requirements for conventional medical practitioners

\section{Practice:}

- Generic laws that also cover the practice of traditional/complementary medicine vs. specific traditional/complementary medicine legislation

- De-criminalization of practice vs. professionalization of practice

- Mono-therapeutic (that is individual traditional/complementary medicine practitioner regulators) vs multi-therapeutic (that is umbrella regulator for all such practitioners) vs. integrated (that is single regulator for traditional/ complementary and conventional medicine practitioners)

- National vs. regional/local standards of practice

- Setting specific standards (for example, hospital vs primary care; public hospital vs. private practice)

- Delegate standard setting to professionals vs specify in legislation 
- Statement of minimum standards vs. statement of limits of practice

- Protection or title vs protection of practice Regulating complementary medical practitioners an international review. Web Kingfund.co.uk

Regulatory models: As with the definition of the products themselves, there is no consistent global approach to regulation with many different frameworks developed that largely reflecting national and regional priorities and needs. That being said, there are a number of common themes and approaches that have been taken internationally.

Where does the category fall within existing legislation? With a few exceptions, notably where traditional forms of health and healing exist, most countries do not regulate dietary supplements as a stand-alone category. Rather, they include them as a subset of existing legislation (Taylor, 2004; Anonymous, 2017a-d). That is they "hang from the hook" that is set in existing legislation. In the past, this was largely a question of whether these products should be considered a subset of drugs or foods; increasingly though, a third option is to capture them under existing regulations for biologics. It is important to note that overarching legislation is often one of the most important factors impacting the type of claim that can be made and what level of scrutiny and oversight will exist. For example, countries that regulate these products as a subset of drugs or therapeutic goods such as Australia, Canada and the European Union (EU) for traditional herbal medicines allow far more specific clinical claims to be made than in a jurisdiction such as the USA where dietary supplements are captured in regulations under the existing food legislation with their advertising regulated by trade regulations (Anonymous, 2017a-d; Anonymous, 2018a-c; USFDA., 2018a, b).

Should they be regulated as a group: As noted above in many jurisdictions dietary supplements are simply captured under the existing food or drug regulations and legislation with no specific consideration for these products in some cases specific regulations have developed to reflect the category. In these cases, two different regulatory models have typically been adopted that reflect their domestic use national priorities and public health needs. In many jurisdictions, the first model applies. Dietary supplements are simply captured under the existing food or drug regulations and legislation. In that model, a wide range of products (typically herbal medicines, traditional medicines and dietary or nutritional supplements) reside under an umbrella term such as dietary supplements in the USA, complementary medicines in Australia or NHP in Canada (Anonymous, 2017a-d; Anonymous, 2018a-c). In the second model, specific regulations are developed to deal with these products. In this case, specific categories are developed with very structured regulatory frameworks for specific types of T\&CMs. This is particularly the case in countries with a strong traditional form of health and healing such as Chinese proprietary medicines in China (TCM), Ayurvedic medicines in India and Kampo medicines in Japan (Anonymous, 2017a-d).

Irrespective of the approach taken, it is rare that one set of regulations will encompass all products commonly considered to be dietary supplement-like. Typical examples of this are guidelines and legislation related to advertising that apply irrespective of whether or not a product is considered to be a dietary supplement.

Common elements of regulatory frameworks: As with other forms of regulations, independent and irrespective of the approach taken, frameworks that deal with dietary supplements may contain a number of common elements in this case often specifically developed to reflect the challenges and nature of the products. These common elements include: process for approval of a product to be sold; provisions related to manufacture and Good Manufacturing Practices (GMPs); reporting of adverse events; controls on labeling related to indications, contraindications and warnings and where claims are permitted, the type and quality of supporting evidence required. Again, the number and nature of these elements applied are determined by the specific regulations in place.

Risk-based approach: Operationally, the regulation of dietary supplements faces a number of issues and challenges not shared with conventional drugs or even food products. Notable amongst these are the sheer number of individual dietary supplements on the domestic markets, often numbering in the tens of thousands and the fact that the sector contains many different types of products often posing very different risks that are grouped together often by the fact that they do not fit under any other regulatory regime. In particular, considerable challenges are posed especially by herbal and traditional medicine products that contain crude botanicals and a complex milieu of potentially active moieties, unlike conventional allopathic pharmaceuticals.

While a completely pre-market approach where all products and manufacturing sites are 'approved' before the dietary supplement is marketed would be the optimal situation given the challenges mentioned above, this is often impractical. This has led to the development of regulatory frameworks that increasingly blend elements looking at products and sites both before they come to market as well as once they are available to consumers or post-market. This regulatory oversight is sometimes referred to as a "life-cycle" approach. Examples of 
post-market regulatory approaches (i.e., once the dietary supplement is on the market) include target audits where dietary supplements already on the market are analyzed for quality or manufacturers are requested to submit evidence they may hold that supports a specific claim. The determining factor on which approach is applied is largely determined by risk posed to the consumer. Since, most dietary supplements when appropriately manufactured are considered to be inherently low risk, increasingly regulatory frameworks are increasingly focused more on post-market review than pre-market licensure. Even in countries that are in many ways socially, economically and legally similar, different approaches to the definition and regulation of dietary supplement health products are evident, although, they contain some common elements. Illustrative examples of this are evident in the different regulatory frameworks in place in the United States, Australia and Canada.

In the United States, dietary supplements are regulated under the Dietary Supplements Health Education Act of 1994 (DSHEA) as a subset of foods and limited to those taken orally. This approach is primarily post-market in nature. However, it does contain pre-market elements. For example, manufacturers must hold evidence to support their claims and they cannot make specific disease treatment claims but only claims related to nutritional support (which includes physiological structure and function) (Anonymous, 2017a-d). All products must carry a disclaimer on the label stating that claims have not been reviewed by the US Food and Drug Administration (FDA). Provisions also include a post-market site audit process for manufacturing sites for Good Manufacturing Practice compliance and mandatory reporting of serious adverse effects by manufacturers. Companies must notify the Food and Drug Administration before marketing products with New Dietary Ingredients (NDI) (Anonymous, 2018a-c). There is at present no indication that DSHEA will be substantially changed or modified by Congress in recent years the regulatory authority has given more attention to the notification and classification of NDIs as well as the importance of Good Manufacturing Practices (GMP) (Anonymous, 2017a-d).

In Australia, although, a small number of these products are captured by a food standard, most are regulated as therapeutic goods under the Australian Therapeutic Goods Act. Products are referred to as complementary medicines and are legally defined as being a listed therapeutic good or a registered therapeutic good. The legislation itself does not define these terms, but a comprehensive set of guidelines describes how they are considered. Most complementary medicines are listed medicines and are managed through an online portal called the Electronic Listing Facility (ELF). Permitted claims are limited to minor, self-limited considerations and those traditional forms of health and healing such as traditional Chinese medicine. Evidence for efficacy is assured through a random and targeted post-market audit system and new list able substances are evaluated pre-market. As with all registered therapeutic goods, registered complementary medicines are evaluated pre-market for safety, quality and efficacy. Manufacturers of either finished listed or registered complementary medicines must undergo an on-site audit to ensure GMP (TGA., 2018).

In 2014, complementary medicines were included within a comprehensive review of regulations for all therapeutic goods and medical devices to be conducted by an external expert panel (TGA., 2016). The Commonwealth government accepted the majority of the recommendations from the panel and preliminary draft legislation was made public in September 2017. Although, one of the recommendations was to keep complementary medicines as a distinct category, some significant changes are proposed, allowing mid-level claims through a new third regulatory route between the listed and registered therapeutic goods process as well as changes to how advertising is approved and compliance management (Anonymous, 2018a-c; Anonymous, 2016a-d).

In Canada, the majority of these dietary supplement products are referred to as Natural Health Products (NHPs) and are considered a subset of drugs under a specific set of regulations-the Natural Health Products Regulations. Products must undergo a premarket assessment for safety, quality and efficacy. This is done in part through an online submission process with permissible claims supported by Health Canada monographs. Producers of NHPs who wish to make novel claims not supported through the monograph process must submit a full dossier of evidence for review. The products can make therapeutic claims but their use is limited to self-care situations. While manufacturers are required to have a valid site license following approved GMP guidelines, no pre-market site audit is needed; the process being primarily paper based (Anonymou, 2017a-d). To address the growing number of NHPs sold in a food-like format, Health Canada has created a new category of food currently defined through regulatory policy called "supplemented foods". The category does allow for some health claims but they are limited reflecting the nature of the products (Anonymous, 2016a-c).

Unlike Australia, Canada is proposing to take different approach and rather than keeping NHPs as a distinct category will include them in a self-care health product category together with non-prescription medicines and cosmetics. The intent of this initiative is to support informed consumer choice through a more consistent regulatory approach to these product categories that is based on risk. Key questions being explored deal 
with topics including evidence needed to support claims, provisions ensuring safety and quality and introduction of cost recovery framework. The overviews above are brief and concise with more detailed information on these country specific approaches to be found through the list of resources in Table 1.

Competing types of evidence: While it is clear that high quality scientific evidence is always required to support the quality of a dietary supplement from a regulatory perspective the same may not always be true with regard the type and nature of the evidence required to support a product claim. Given the natur of the dietary supplement sector and the fact that it often encompasses traditional medicines with a long history of use the question faced by regulators is how to balance the need for robust scientific evidence with a respect for diverse forms of health and healing.

Globally, no consistent approach has been taken in answering this question. In some jurisdictions such as Canada and Australia, the approach has been to link the form of evidence whether it be traditional or evidence based from scientific research to the level and type of claim that can be made. In these cases, typically products based on traditional evidence making traditional health care claims are 'approved' according to pre-cleared and approved sources of information such as monographs or labeling standards. For products making higher level, clinical claims in a way similar to that for conventional pharmaceuticals, companies must supply a full dossier with appropriate supporting evidence such as that from Randomized Controlled Trials (RCTs) (Anonymous, 2017a-d; TGA., 2018). In many countries such as the United States with no pre-market approval framework system, claims that can be made are more limited (Taylor, 2004; Anonymous, 2017a-d). In countries with long-established traditional forms of medicines such as in China, India and Japan, specific regulatory frameworks have been developed for these types of products with the type of claim that can be made and the evidence required to reflect this approach (Anonymous, 2017a-d).

As the dietary supplement sector matures and develops and the market for raw ingredients becomes more global, establishing a balance between evidence generated by scientific research and that coming from traditional forms of health and healing is becoming increasingly demanding. This will be discussed later.

Evolving regulatory landscape-challenging issues: International regulatory frameworks are still considered by many to be a new and novel sector, although, many of them are now more than two decades old. They were developed to reflect a time when the sector and nature of the market, not to mention the needs and demands of the consumer were very different. This has meant that some decisions made in the past around policies and regulatory decisions may need to be revisited. These include the need to evaluate evidence of the "grandfathering" of dietary supplements already on the market when new regulations were implemented, the need to ensure that approaches are sustainable through cost-recovery mechanisms and the more global nature of the market place. Table 1 provides links to some of the regulatory frameworks of different countries that provide insights into the ways issues are dealt with in them. Some of the key issues that commonly arise are detailed in the next session.

Evaluating evidence for product claims: As the market for dietary supplements has increased, so has the amount and diversity of scientific evidence and research to support or not support, their use. This market is made more complex when there are conflicting evidence bases and conflicting ways for evaluating them. For example, how or should, traditional evidence be evaluated within the framework of traditional healing theories or those of allopathic evidence based medicine what should be done when evidence from traditional forms of health and healing are not supported by more conventional evaluation mechanisms such as randomized clinical trials and how can consumers, often wanting to explore both conventional and traditional medicine be supported in making informed choices about including or not including, these products in their health care options.

The original concept of evidence based medicine is based on three basic premises-individual clinical expertise, the best external evidence and patient's values and expectations (Anonymous, 2017a-d). The challenge faced by the regulator is to ensure that these are in play and to support consumers in making informed choices that are often made in a self-care setting.

Questions at the regulatory interface: It has never been easy to distinguish between a dietary supplement and other categories such as conventional foods, drugs and biologics. As all these sectors have evolved, this question of product classification has become even more complex. Two of the main questions at the regulatory interface are what are the boundaries are between dietary supplements and conventional foods and between dietary supplements and over-the-counter drugs? As the popularity of dietary supplements available in a food-like format such as a pre-prepared drink or bar has increased, the line between what a consumer would understand to be a food as compared to a dietary supplement has become increasingly blurred. In essence, how does the regulator provide for appropriate regulatory oversight? This has been particularly challenging for those jurisdictions that consider these products as a sub-set of drugs with regulation and often legislation governing them that is very different from that for foods. In these cases, the regulatory frameworks are more specific to such dosage forms as capsules, tablets and tinctures. The challenge is one primarily of balance in providing a regulatory 
approach that is appropriate and not unnecessarily restrictive with the need to ensure that consumers are aware that these food-like dietary supplements that they are considering are not typical foods. This lack of clarity is also challenging for the private sector in determining what regulatory framework applies to a product, either food or drug, that they wish to develop and bring to market. In Canada, this concern required the government to create a new category called "supplemented foods" distinct from NHPs where products in a food like format are considered as a subset of foods and not as natural health products (Anonymous, 2016a-c). In other jurisdictions such as Australia, authority has been given to the respective regulators to deem something to be either a therapeutic good or a food based a specific set of criteria (Anonymous, 2017a-d).

The challenge at the Over-The-Counter (OTC)/ dietary supplement interface is even more pronounced. A number of herbal medicines with a long history of use within the conventional health care model such as senna and cascara are regulated in most countries as OTC drugs rather than dietary supplements. As described above, Health Canada is proposing to address this issue in part by considering both NHPs and OTC drugs within a single regulatory approach for self-care products.

Working on the global stage: Although, science and research may be global, regulations are still made primarily to reflect domestic needs and pressures. This poses a challenge regarding dietary supplements and dietary supplement ingredients that are now often sourced and/or manufactured outside of the country where they are sold. In spite of calls for regulatory harmonization, examples of true harmonization are limited to regions such as countries in the Association of South East Asian Nations (ASEAN) with the lack of a coherent and consistent regulatory approach prohibiting this globally (Anonymous, 2019). Even if regulatory harmonization is not possible, regulatory cooperation is often a viable option, taking into account inputs from stakeholder groups such as industry and not just governments. For example to support cooperation between regulators in 2005 in Ottawa, the World Health Organization supported the creation of the International Cooperation on Herbal Medicine (IRCH)(WHO., 2005). IRCH now has over twenty members and provides a forum and mechanism for regulators to share information on safety issues and common challenges they all face (Gorman et al., 2013). Increasingly governments are working together as well as with other stakeholders such as industry and consumers to address common problems and in some cases to provide regulatory decisions in one jurisdiction that can be used as a basis for action in another.

Strengthening product quality: As the dietary supplement market has become more global and lucrative, so have the importance of ensuring product quality and the challenges in doing so. There are increasing numbers of cases of adverse reactions and some fatalities due to contaminants or adulterants in the product rather than in the dietary supplement ingredients themselves. In some cases this has been due to intentional fraud by producers of these poor quality products who have developed sophisticated methods for overcoming existing regulations and oversight. This situation is explored in greater depth elsewhere in this study.

Need for continued science in support of regulation: Irrespective of whether the goal is to support production of high quality products or to develop, apply or modify methods for evaluation of evidence in support of claims, the need for robust and relevant science and research on dietary supplements has never been more necessary. As regulatory frameworks evolve, many of the questions posed above will need to be addressed, balancing the need for robust science with a respect for traditional forms of health and healing.

\section{Challenges: scientific perspectives}

Issues involving human requirements: Scientists often disagree about definitions of human requirements for bioactives and the implications for supplements. They differ on whether some non-nutrient bioactives are required for certain population subgroups and also on the health effects associated with the use of non-nutrient bioactives. It has been known for over 100 years that inborn errors of nutrient metabolism exist that can be remediated by supplying the lacking nutrient that has become conditionally essential. However, it is not clear that such a model based on single gene defects is useful for the amelioration of multigenic complex diseases. It is unclear that there are large numbers of individuals with common diseases and conditions such as type 2 diabetes or depression whose unique genetic characteristics cause them to have special nutritional requirements requiring supplements or medical foods (De Toro-Martin et al., 2017).

Discoveries of genetic polymorphisms and the advent of inexpensive genetic tests that are widely available to consumers have nutritional implications. They have led to the rise of personalized or "precision nutrition" (World Health Organization, 2013) and to the proliferation of boutique "personalized" eating plans and "precision" dietary supplements supposedly tailored to an individual's genetic profile. The extent to which such supplements are efficacious in reducing chronic degenerative disease remains to be determined.

Supplement quality, safety and efficacy: Challenges remain on the appropriate means for assuring supplement quality, safety and efficacy. 
Quality: Regulators, health professionals and manufacturers often disagree on how much quality testing is necessary for supplements. This is echoed by the World Health Organization's Strategy on Traditional Medicines 2014-2023 (Drueke and Massy, 2012) where quality is seen as a cornerstone of the sector. Botanical extracts and blends present particular challenges for detecting misidentification and contamination. The presence of adulterants and contaminants of both a biological and chemical nature in supplements is also challenging. Certain categories of supplements such as athletic performance, sexual performance and weight loss products are particularly prone to the deliberate "spiking" with unlabeled extraneous or synthetic substances to confuse analytical techniques and even occasionally the addition of active synthetic drugs. Purity is a special problem for individuals with inborn errors of metabolism for specific nutrients such as vitamin B-6 or choline who require reliable, high quality sources of the nutrient. In countries that do not require that added nutrients be pharmaceutical grade or provide nutrients free to such patients, afflicted individuals must buy products that vary greatly in their quality on the open market.

The scientific challenges involved in all of the problems cited above depend in part on the adequacy and application of analytical methods. Analytical methods and reference standards are lacking for many of the thousands of different bioactive ingredients in dietary supplements. There is still disagreement about whether only a single officially endorsed method of analysis is acceptable. Any analytical method that is appropriately calibrated to a recognized reference standard should suffice but the onus is on the user of the method to demonstrate that affirmative requirements are met and that the method is suitable for its intended use and yields results that are accurate and precise. Methods that are suitable for foods may not be so for dietary supplements. Opinions also differ on whether government or the private sector is responsible for developing reference standards and analytical methods and if the private sector develops them, how they can be both kept independent and objective and made publicly available to avoid duplication of effort while preserving the marketing advantage of the developer. Tension also exists between researchers who desire ever more precise analytical methods for ingredients in dietary supplements and manufacturers who are concerned about the expertise and monetary costs required to apply some of the methods. A balance needs to be struck between the two.

Safety: Apart from concerns related to product quality, the safety of dietary supplements depends largely on dose. High doses of some nutrients are more likely to pose problems than others, although, there is disagreement about the levels at which problems arise. For example, some dialysis patients who are receiving very large doses of calcium and the active form of vitamin $\mathrm{D}$ on a chronic basis may exceed the Tolerable Upper Level (UL) and incur adverse effects on health including calcification of the soft tissues (Rooney et al., 2017). Very high doses of vitamin D may also cause adverse effects in people with normal kidney function (Prentice et al., 2013). There is little evidence that usual doses and forms of these nutrients give rise to health problems (Fulgoni et al., 2011). The possibilities of excessive intakes of nutrients from dietary supplements are greater in countries with programs to fortify their food supplies than in others and therefore, they must also be evaluated (Boyles et al., 2016; Dwyer et al., 2015, 2014; Yetley et al., 2016).

Dose-response data for establishing safe levels of intakes of non-nutrient bioactives in supplements is frequently lacking (Gaine et al., 2013; Brown, 2017a, b). Some dietary supplements containing non-target herbs added intentionally (like germander as an adulterant for skullcap) or others such as black cohosh, kava extract, green tea and others have been associated with liver injures of various types even after taking into account concomitant use with acetaminophen and alcohol and consumption while fasting (Saldanha et al., 2015). Extracts that are used in bodybuilding and weight loss have also been linked to liver injury. This has led to studies of the composition of different supplements (Sander et al., 2012; De Boer, 2017). Causes of liver toxicity from supplements appear to be due to insufficient regulatory authority, inaccurate product labeling, adulterants and inconsistent sourcing of ingredients (Avigan et al., 2016). There is controversy about whether evidence of causality is sufficient for regulators to take action against supplements that seem to pose a hepatotoxic risk (Brown, 2017). Some possible actions include requirements for warning labels with usage instructions as is done for drugs or/and removal of products from the market. Adulterated or fraudulent tainted products sold as dietary supplements are already illegal and subject to recall (Gardiner et al., 2008).

Interactions of some ingredients in supplements with other dietary supplements, nutrients, prescription or over-the-counter drugs are well documented. Of particular concern are adverse reactions occurring with commonly used medications such as anti-hypertensive and cardiovascular preparations (Tsai et al., 2012). In addition, much interest focuses around concomitant use of herbal medicines such as St. John's Wort which has been shown to alter drug metabolism of a number of drugs notably those used in the treatment of HIV/AIDS, warfarin, insulin, aspirin and digoxin (Gagnier et al., 2006a, b).

Efficacy: Among the most hotly debated issues in supplement research is the type and amount of evidence needed to demonstrate the efficacy of dietary supplements. Many of the issues involving efficacy 
include those common in testing of all medications such as study designs, significance testing, appropriate outcomes, effect sizes, acceptable biomarkers of effect, and the differences between statistical and clinical significance. In order to be efficacious, dietary supplements must be bioavailable and yet in some countries regulations do not require testing of supplements for disintegration and dissolution and some products on the market fail such tests. This is a matter of concern both to researchers and regulators, since, such results have a negative impact on studies of dietary supplement efficacy. In-vitro methods are available for testing disintegration and dissolution of drugs and these are adaptable for use with dietary supplement products. Regulators in some countries insist on changes in health outcomes or in validated surrogate biochemical markers of effect on the causal pathway to a health or performance outcome. Others accept changes in intermediary biochemical markers that may or may not be surrogates of health outcomes. These considerations have come to the fore because supplements on the market in some countries apparently have little or no demonstrated efficacy. For example, one recent review of 63 randomized, placebo-controlled clinical trials of dietary supplements in Western adults found that in 45 of them no benefits were found, 10 showed a trend toward harm and 2 showed a trend toward benefit while 4 reported actual harm and 2 both harms and benefits only vitamin D and omega 3 fatty acids had strong enough benefits and lack of harm to suggest possible efficacy (Marik and Flemmer, 2012). This is an area of controversy that is highly polarized with questions being raised that depend on the type of dietary supplement being used notably herbal medicines, the quality of the studies included in the review and additional factors such as product quality of the supplement being evaluated that need to be taken into account (Blumberg et al., 2017).

Standards of efficacy for traditional natural products: The traditional use of Chinese medicines, Ayurvedic medicines and other remedies is embedded in larger healing systems and cultural or metaphysical beliefs that are part of user's larger and more holistic world views. Should usual standards for efficacy should apply to them when they are used in the traditional manner? Clearly such uses are quite different than the use of a single product or ingredient at much higher traditional doses and without such a cultural context.

Policy: Although, policy issues arise with all types of dietary supplements, the examples below will focus on nutrient-containing dietary supplements, since, these are particularly germane to discussions of nutritional status.

Nutrient supplements are only one of many strategies for improving nutrient intakes: There are many strategies for filling nutrient gaps in dietary intakes. They include nutrition education on appropriate food choices, fortification and enrichment that add nutrients to staple foods, genetic engineering that increases the nutrient content of a commodity itself either by genetic engineering/biotechnology, biofortification involving conventional breeding and the use of nutrient containing dietary supplements. Dietary supplements provide concentrated sources of bioactives that are low or lacking in some individual's ordinary dietary intakes. The supplements can be used selectively by those whose diets have gaps in them. However, supplements have disadvantages. Their use depends upon individual motivations. Because they provide concentrated sources of bioactives at relatively high levels, they may increase the risks that some individuals will ingest excessive quantities and suffer health risks. Moreover, since, dietary supplements can contain ingredients that lack a history of safe use their long-term health effects may be unknown. The advantages and disadvantages of dietary supplements as a strategy to improve dietary intakes therefore must be carefully considered.

Supplementation as a strategy to achieve nutritional adequacy: The cost-effectiveness of using supplements to fill gaps in nutrient intakes as opposed to other means such as fortification or nutrition education varies from one nutrient to another and by country and so, each situation is unique and must be evaluated independently. There are also questions about what the supplement should be if supplementation is chosen. In countries where nutrient containing dietary supplements are common, the use of Multivitamin-multi-mineral (MVM) supplements is often associated with a greater proportion of the population reaching the Estimated Average Requirement (EAR) for nutrients (Raghavan et al., 2016). However, for some of these nutrients, intakes are already adequate, so that, the increased intakes may do little good and in some cases supplements may increase the risk of exceeding the Upper safe Level (UL) of intakes.

Monitoring of supplement use: Monitoring of supplement use is particularly important in countries where premarket approval is not required to detect potential adverse reactions. Dietary indicators are known to be imprecise and estimates of usual intake are lacking for many nutrients (Centers for Disease Control and Prevention, 2014). Biochemical indicators of deficiency are often not well linked with adverse health outcomes, underscoring the need for more attention to be paid to the development of agreed on measures of deficiency and excess (Bailey et al., 2015). Recent work on key nutrient biomarkers is now available, facilitating the monitoring of high risk groups such as pregnant women for folate status (Branum et al., 2013; Balk et al., 2017). 
Authoritative recommendations for dietary supplements: Health and nutrition experts differ on whether it is appropriate to include recommendations for nutrient containing dietary supplements in national health promotion and disease prevention recommendations. Many countries opt to recommend that adequate nutrient intake for the general public be achieved solely from foods and reserve recommendations of specific nutrient supplements for specific subgroups in the population. Others recommend only food alone with no recommendations for special populations.

Inclusion of dietary supplements in food programs to reduce malnutrition: There is pressure by industry to include MVM or other dietary supplements in food programs. However, there is little evidence that the target groups are deficient in the ingredients in the supplements, nor has it been demonstrated that provision of a supplement leads to better health outcomes.

Stimulating Innovation: The development of new and more highly bioavailable forms of the nutrients, timed release, dosage forms, novel bioactive constituents and the appropriate application of new technologies such as nanotechnology are all important but some pose new scientific and regulatory challenges.

Case study: Office of Dietary Supplements (ODS), National Institutes of Health (NIH), USA: This case study highlights some examples of dietary supplement research supported by or conducted at the ODS and provides some research tools it has developed that may be useful resources for scientists both there and abroad.

Background: Since, its establishment in 1995 as part of the implementation of the Dietary Supplement and Health Education Act (Taylor, 2004; Anonymous, 2017a-d) of 1994, the ODS is the lead federal agency devoted to the scientific exploration of dietary supplements. Its mission is to support, conduct and coordinate scientific research and provide intellectual leadership to strengthen the knowledge and understanding of dietary supplements in order to enhance the US population's health and quality of life. ODS's four goals are to: expand the scientific knowledge base on dietary supplements by stimulating and supporting a full range of biomedical research and by developing and contributing to collaborative initiatives, workshops, meetings and conferences; enhance the dietary supplement research workforce through training and career development; foster development and dissemination of research resources and tools to enhance the quality of dietary supplement research and translate dietary supplement research findings into useful information for consumers, health professionals, researchers and policymakers. Several of its major initiatives that have expanded the scientific knowledge base on dietary supplements are described elsewhere in this special issue of Nutrients. They include studies to clarify the implications for public health of omega-3 fatty acids (Ershow et al., 2018), iodine (Taylor et al., 2017), vitamin D (Brannon and Taylor, 2017) and iron (Kuszak et al., 2016).

Research resources and tools: This study provides the details on freely available research resources developed by ODS that are available for scientists to use to enhance the quality of dietary supplement research and meet public health priorities with a focus on those that may be useful to scientists in other countries.

Analytical methods for dietary supplements: The rigorous assessment of dietary supplement ingredients requires accurate, precise and reliable analytical methods and matching reference materials. The ODS Analytical Methods and Reference Materials program accelerates the creation and dissemination of validated methods and reference materials. It provides resources for characterization and verification of supplement product content that enhance the reliability and reproducibility of research using these products and supports product quality (Betz et al., 2007). The genesis of the program was the paucity of publicly available methods for the analysis of supplement ingredients (Betz et al., 2011; LaBudde and Harnly, 2012). In 2000, the US dietary supplement community tended to use proprietary or compendial methods for quality control operations and scientists and laboratories often kept their proprietary methods to themselves. Negative publicity about discrepancies between label claims and the results of product testing performed by third parties led to some unsuccessful efforts on the part of the industry to pay a laboratory to develop and validate methods through the Association of Official Analytical Chemists International (AOACI). The program was not successful for several reasons including lack of expert technical guidance and conflicting sponsor priorities. However, this early effort led to a collaboration between trade associations, ODS, the AOACI, the United States Pharmacopoeia (USP), NSF International and others in an attempt to establish standard methods for dietary supplement analysis. The ODS became involved because explicit wording in DSHEA required the Government to use "publicly available" analytical methods for enforcement actions involving dietary supplements. In response to the need for such publicly available methods and to support efforts to validate methods used in biomedical research on dietary supplement ingredients, ODS established the Analytical Methods and Reference Materials (AMRM) program in 2002. ODS has been involved in sponsoring the creation of AOAC Official Methods of AnalysisT for dietary 
supplements and in the development and dissemination of numerous analytical methods and reference materials for 15 ingredients in dietary supplements in the USA, 32 botanical identification and documentation projects and 45 studies determining contamination and adulterants. It has also helped to develop guidance on the validation of identity methods for botanical ingredients (Betz et al., 2014) and the conduct of single-laboratory validation studies for dietary supplements, Appendix K, AOAC Official Methods of Analysis and provided guidance to evaluation of the literature on botanical supplements (Betz and Hardy, 2014; Brooks and Sempos, 2017). The portion of the ODS website includes a searchable database of analytical methods; these can be accessed at: https://ods.od.nih.gov/Research/AMRMProgramWebsit e.aspx. ODS also supports the Dietary Supplement Laboratory Quality Assurance Program in which participants measure concentrations of active and/or marker compounds and nutritional and toxic elements in practice and test materials. Exercises have included water and fat-soluble vitamins, nutritional and toxic elements, fatty acids, contaminants (e.g., aflatoxins, Polyaromatic Hydrocarbons (PAH's)) and botanical markers (e.g., phytosterols and flavonoids).

Reference materials: ODS supports the development of certified reference materials for dietary supplement ingredients with assigned values for concentrations of active and/or marker compounds, pesticides and toxic metals to assist in the verification of product label claims and in quality control during the manufacturing process. A reference material is a material that is sufficiently homogeneous and stable with respect to one or more specified properties which have been established to be fit for its intended use in a measurement process. A Certified Reference Material (CRM) is a reference material characterized by a metrologically valid procedure for one or more specified properties, accompanied by a certificate that provides the value of the specified property, its associated uncertainty and a statement of metrological traceability. Certified reference materials can be used for laboratory proficiency studies, methods development, method verification and method validation studies. Calibration standards are the single chemical entities necessary for construction of calibration curves for quantitative analysis and for confirming analyte identity. Several processes are used to produce calibration standards. ODS provided funding to the US Department of Commerce's National Institute of Standards and Technology (NIST) for the development and distribution of calibration standard solutions and matrix standard reference materials $\left(\mathrm{SRM}^{\mathbb{B}}\right.$; a NIST-trademarked type of CRM). The materials fall into one of the following categories: pure chemical entities or their mixtures including many nutrients and other ingredients in dietary supplements for use in establishing analyte identity and for calibrating instruments; natural matrix materials that represent the supply chain of a particular dietary supplement, e.g., biomass (ginkgo leaves and powder), processed botanical ingredient (ginkgo extract), finished product; natural matrix materials that cover a range of analytes including nutritional compounds, botanical marker compounds and compounds with known health concerns (heavy metals, pesticides, plant toxins) and Clinical materials that can be used to assist clinical laboratories assess nutrient status or exposure such as the measure of measure of vitamin D status commonly used around the world, serum 25-hydroxyvitamin D (Phinney et al., 2017, 2012; Dwyer et al., 2008). ODS is now expanding efforts to develop biomarkers of nutrient exposure and status in blood and other biological specimens in relation to chronic disease risk in individuals and populations. ODS has worked with NIST to produce and make available reference materials for calibration of various laboratory methods. Supplementary Table S1 shows NIST Standard Reference Materials $\left(\mathrm{SRM}^{\circledR}\right)$ now available. Supplementary Table S2 shows dietary supplement and nutritional assessment SRMs that are currently in progress.

Dietary supplement databases: Two databases have been developed by ODS that are described elsewhere in detail (Dwyer et al., 2014, 2017; Saldanha et al., 2015; Lichtenstein et al., 2009). The goal of the Dietary Supplement Label Database (DSLD) is to include labels for virtually all dietary supplements sold in the USA. This provides all the information on the product label including composition, claims and manufacturer contact information. It now contains over 72,000 dietary supplement labels with new labels added at the rate of 1000 per month. Used together with food composition databases it is possible to estimate total daily intakes of nutrients and other bioactive ingredients from both foods and dietary supplements. A mobile version of DSLD is now available for use on smart phones to enhance consumer access to it (Andrews, 2017; Saldanha et al., 2015; Lichtenstein et al., 2009). It is primarily aimed at researchers and so contains information about products that are currently on the market as well as those that have been removed from the market. The Dietary Supplement Ingredient Database (DSID) provides analytically derived information on the amount of labeled ingredients of a representative sample of commonly used categories of supplement products sold in the USA including adult, child and prenatal MVM supplements and omega-3 fatty acids. DSID is now being expanded to examine botanicals and other ingredients in supplements that are of public health interest such as green tea products. Calculators included with the DSID permit a consumer to examine 
how closely the labeled contents of a nutrient in a product compare to chemical analyses of all products in the category (Saldanha et al., 2015).

\section{MATERIALS AND METHODS}

Nutrition research methods and review methodology: Systematic reviews of dietary supplements require special techniques. ODS has sponsored a series of technical reports on the application of review methodology to the field of nutrition and dietary supplements (Helfand and Balshem, 2010; Trikalinos et al., 2012; Moorthy et al., 2011; Brannon et al., 2014; Ko et al., 2014). Staff have also collaborated in performing systematic reviews with other groups (Brooks et al., 2016; Bailey et al., 2013a, b).

Population-based monitoring of dietary supplement use: In collaboration with the National Health and Nutrition Examination Survey (NHANES) of the National Center for Health Statistics, O DS investigates patterns of dietary supplement use using national and other large cohorts and assesses supplement's effects on total nutrient intakes. Several studies have focused on adults (Bailey et al., 2013a, b), children (Berner et al., 2014; Taylor et al., 2015) and others in the population and their supplement use. Other studies have focused on the contributions to total intakes of nutrients made by dietary supplements. Investigators at ODS have been active in funding monitoring efforts on the links between intakes of folic acid and health (Pfeiffer et al., 2012). They have devoted particular attention to blood levels of folic acid and dietary intake patterns that are associated with very low and very high intakes of the nutrient (Pfeiffer et al., 2016; Pfeiffer et al., 2017). The survey methods used are well documented and they may be useful for those in other countries planning similar population-based surveys to consult (Pandey et al., 2008, 2013).

The motivations for use of dietary supplements are also documented; they often differ from those specified in regulations. NHANES contains several items that are consumer tested and available for use in other surveys on motivations. Knowledge of motivations can improve understanding of how people use these products and may provide clues for encouraging appropriate supplement use.

Translation of supplement science for health professionals and the public: ODS has produced and periodically updates a library of more than two dozen fact sheets on the ingredients in supplements such as vitamin $\mathrm{D}$, magnesium and special products such as MVM supplements and products marketed for weight loss. There is a detailed version for professionals that is complete with detailed references as well as easy-to-read versions for consumers in both English and Spanish. ODS also works with the National Library of Medicine (NLM) to produce and update a Dietary Supplement Subset of NLM's PubMed. The National Center for Complementary and Integrative Health $(\mathrm{NCCIH})$ at NIH produces a series of fact sheets on many botanicals and other non-nutrient bioactives in supplements that are also useful. They can be accessed at https://www.nccih.nih.gov. ODS also hosts an intensive, free 3-day course on issues in dietary supplement research annually for researchers. Further information about these and other projects is accessible at: https://www.ods.od.nih.gov.

\section{RESULTS AND DISCUSSION}

Other resources: In order to foster the development of appropriate study methods for dietary supplement research, ODS sponsors workshops on the latest knowledge and emerging approaches to the study of dietary supplements. It also supports the development of cutting-edge approaches to elucidate the mechanisms of action of complex botanical dietary supplements. It co-funds the Centers for Advancing Research on Natural Products (CARBON) with the NCCIM including its program to develop high content high throughput methods to rapidly generate hypotheses on active compounds and the cellular targets. These and other resources are announced as they become available on the ODS website.

Fostering use of systematic evidence reviews in policy making and clinical practice: ODS has strengthened the scientific framework for developing dietary recommendations by encouraging the incorporation of systematic reviews into the development of the DRI. It has sponsored 18 systematic reviews on topics related to dietary supplements. These include ephedra, B vitamins, MVM supplements, omega-3 fatty acids, soy, probiotics and vitamin D. The ephedra systematic review was helpful to the US government in banning ephedra products from the US market. The systematic reviews of omega-3 fatty acids funded over a decade ago and more recent updates on their associations with cardiovascular disease and infant health outcomes have been useful for planning intervention programs as well as for regulatory purposes. Current AHRQ reviews are available on the AHRQ website (https://www.ahrq.gov).

Medicinal plants used in alternative/traditional medicines: India is the largest producer of medicinal plants. There are currently about 250,000 registered medical practitioners of the Ayurvedic system as compared to about 700,000 of the modern medicine. In India, around 20,000 medicinal plants have been recorded 
Bot. Res. J., 12 (1-4): 1-30, 2019

Table 2: Impact of modern food concept in required nutrition (Patwardhan et al., 2005; Mashelkar, 2008; Cooper, 2008; Cooper, 2008; Ghodke et al., 2011; Cooper, 2005; Gavaghan, 1994)

\begin{tabular}{|c|c|c|c|}
\hline Nutrients & Intake by traditional ways & Intake by modern ways & Effect on nutrient intake \\
\hline $\begin{array}{l}\text { Water soluble vitamins } \\
\text { (vitamins B and C) and minerals }\end{array}$ & $\begin{array}{l}\text { Vegetables used for cooking } \\
\text { were/are fresh }\end{array}$ & $\begin{array}{l}\text { Freezing and packaging of the } \\
\text { cut vegetables and minerals }\end{array}$ & Loss of ascorbic acid, water soluble vitamins \\
\hline $\begin{array}{l}\text { Proteins, minerals and vitamin B } \\
\text { complex }\end{array}$ & $\begin{array}{l}\text { Manual processing of cereals } \\
\text { without polishing }\end{array}$ & Milling and polishing of cereals & $\begin{array}{l}\text { Reduces protein, minerals and vitamin B } \\
\text { complex }\end{array}$ \\
\hline $\begin{array}{l}\text { Calcium, iron, thiamine and } \\
\text { niacin }\end{array}$ & Fresh grinding at home & $\begin{array}{l}\text { Heavy milling and poor storage } \\
\text { conditions }\end{array}$ & Loss of calcium, iron, thiamin and niacin \\
\hline Iron & Cooking in iron pot & $\begin{array}{l}\text { Food generally cooked in cookware } \\
\text { like nonstick and Teflon-coated } \\
\text { utensils }\end{array}$ & $\begin{array}{l}\text { The benefit of organic iron from the } \\
\text { conventional iron pot is not obtained by } \\
\text { using modern cookware }\end{array}$ \\
\hline Copper & $\begin{array}{l}\text { Storing of water and cooking use } \\
\text { of copper vessels }\end{array}$ & $\begin{array}{l}\text { Stainless steel utensils and } \\
\text { plastic wares }\end{array}$ & $\begin{array}{l}\text { Copper required in minor amount which } \\
\text { is not gained from modern utensils used } \\
\text { today. Deficiency is known to cause chronic } \\
\text { diarrhea, malabsorption problems and } \\
\text { reduce immunity. Use of plastic containers } \\
\text { is also harmful }\end{array}$ \\
\hline
\end{tabular}

however, traditional practitioners use only 7,000-7,500 plants for curing different diseases. The proportion of use of plants in the different Indian systems of medicine is Ayurveda 2000, Siddha 1300, Unani 1000, Homeopathy 800, Tibetan 500, Modern 200 and Folk 4500. In India, around 25,000 effective plant-based formulations are used in traditional and folk medicine. More than 1.5 million practitioners are using the traditional medicinal system for health care in India. It is estimated that more than 7800 manufacturing units are involved in the production of natural health products and traditional plant-based formulations in India which requires more than 2000 tons of medicinal plant raw material annually. More than 1500 herbals are sold as dietary supplements or ethnic traditional medicines (Patwardhan et al., 2005; Mashelkar, 2008) (Table 2).

More than $80 \%$ of people in developing countries cannot afford the most basic medical procedures, drugs and vaccines. Among wealthier populations in both developed and developing countries, complementary and alternative practices are popular although proof of their safety and effectiveness is modest. Evidence-based research in Ayurveda is receiving larger acceptance in India and abroad (Mashelkar, 2008; Cooper, 2008a, b; Ghodke et al., 2011). The National Center for Complementary and Alternative Medicine has been inaugurated as the United States Federal Government's lead agency for scientific research in this arena of medicine. Its mission is to explore complementary and alternative healing practices in the context of rigorous science, support sophisticated research, train researchers, disseminate information to the public on the modalities that work and explain the scientific rationale underlying discoveries. The center is committed to explore and fund all such therapies for which there is sufficient preliminary data, compelling public health need and ethical justifications (Cooper, 2005; Gavaghan, 1994) (Table 3).

The nomenclature for nutraceuticals is based on the segments it constitutes. In Canada, this term is natural health products in USA, it is called dietary supplements, and in Japan it is called foods for special health use. There are distinct definitions and regulations for dietary supplements and functional foods in USA, Canada and Europe. In Japan, dietary supplements and functional foods are governed under the same set of regulations. USA and Canada actually list the constituents that a product must have to be called a nutraceutical whereas Europe and Japan just provide general guidelines on the properties that a product should have to be called a nutraceutical. Traditional and herbal medicines are included in the definition of dietary or nutritional supplements in Canada. Japan does not mention traditional herbal medicines under functional foods for special health use.

Herbs and plants can be processed and can be taken in different ways and forms, and they include the whole herb, teas, syrup, essential oils, ointments, salves, rubs, capsules and tablets that contain a ground or powdered form of a raw herb or its dried extract. Plants and herbs extract vary in the solvent used for extraction, temperature and extraction time and include alcoholic extracts (tinctures), vinegars (acetic acid extracts), hot water extract (tisanes), long-term boiled extract, usually roots or bark (decoctions) and cold infusion of plants (macerates). There is no standardization and components of an herbal extract or a product are likely to vary significantly between batches and producers (Wachtel-Galor S, Benzie IFF. Herbal Medicine: An Introduction to Its History, Usage, Regulation, Current Trends, and Research Needs. In: Benzie IFF, Wachtel-Galor S, editors. Herbal Medicine: Biomolecular and Clinical Aspects. 2nd edition. Boca Raton (FL): CRC Press/Taylor \& Francis; 2011. Chapter 1. Available from: https: //www.ncb i.nlm.nih.gov/books/NBK92773/) (Fig. 4 and Table 4).

Future needs: Attitudes toward safety, efficacy and values about what is important in food and life will be important in determining future needs involving supplement science in the countries we have discussed 
Bot. Res. J., 12 (1-4): 1-30, 2019

Table 3: Some common medicinal plants having nutraceutical potential and their primary use in traditional medicine (Patwardhan et al., 2005; Mashelkar, 2008; Cooper, 2008a, b; Ghodke et al., 2011; Cooper, 2005; Gavaghan, 1994; Pandey et al., 2013)

\begin{tabular}{ll}
\hline Plant name & Common nam \\
\hline Asparagus racemosus Willd & Shatavari \\
Commiphora mukul Engl. & Guggul \\
& \\
Cyperus scariosus $\mathrm{Br}$. & Nagarmusta \\
Garcinia cambogia $\mathrm{Dr}$ & Garcinia
\end{tabular}

Glycyrrhiza glabra L. Yashtimadhu, Licorice

Gymnema sylvestre R. Br. Gurmarar

Melia azadirachta $\mathrm{L}$ Nimba, Neem

Momordica charantia L. Karela, Bitter melon

Moringa pterygosperma Gaertn Shigru, Horseradish tree

Mucuna pruriens Baker Kiwanch, Kapikachchhu, Cow-itch plant

Nardostachys jatamansi DC. Jatamansi, Musk root

Piper longum L.

Pippali, Indian Long Pepper Uses

A potent Ayurvedic rejuvenative. It supplies many female hormones and mostly recommended for those women who have hysterectomies. It also helps to maintain urinary tract and strengthens the immune system and also purifies the blood A major ingredient in joint and immunocare and regarded as a remedy in Ayurvedic medicine; it increases white blood cell count to possess strong immuno-modulating properties. It also protects against the common cold as well as used in various other conditions like lower cholesterol and triglycerides while maintaining the HDL to LDL ratio

Useful in supporting healthy genitourinary system and have hepatoprotective properties

Fruits contain biologically active compounds $\left(^{-}\right)$hydroxycitric acid which is known to inhibit the synthesis of lipids and fatty acids. HCA inhibits the enzyme ATP-citrate lyase that leads to reduce production of acetyl CoA which is a key substance in fat and carbohydrate metabolism. Therefore, formation of LDL and triglycerides is very low. It also suppresses appetite by promoting synthesis of glycogen. That way the brain gets signals of fullness and satisfaction sooner. Garcinia contains significant amounts of vitamin $\mathrm{C}$ and used as a heart tonic It is a versatile medicine in India and China, for gastrointestinal health. It is a mild laxative, soothes and tones the mucous membranes and relieves muscle spasms. It is an antioxidant, cancer protecting, botanical boosting and certain immune functions such as interferon production. Its mode of action is as an antimutagen, preventing damage to genetic material that can eventually result in cancer.

Its Sanskrit name means literally "sugar destroyer," has a glycolytic action and reduces the strength of a glucose solution. It has been used in Ayurveda to regulate sugar metabolism for several centuries. It increases insulin production, regeneration of pancreas cells and the site of insulin production. Another property is abolishing the taste of sugar, so that, Gurmarar has been effective to suppress and neutralize the craving for sweets

It has strong health alleviating activity, used as a tonic and astringent that promotes healing. The extract has antispasmodic action. Its usage in Ayurvedic medicine for thousands of years has proved its detoxifying properties. It has shown most beneficial effects for the circulatory, digestive, respiratory and urinary systems

Karela has been widely used in Ayurvedic medicine. It contains Gurmarin, a polypeptide considered to be similar to bovine insulin and has a strong sugar regulating effect by suppressing the neural responses to sweet taste stimuli Shigru contains physiologically active principles that is effective in a broad range of health needs. It contains "Pterygospermin," an antibiotic-like substance It is a good natural source of L. dopa. In the Ayurvedic system it is reported as an effective tonic for nervous system. Studies have demonstrated its usefulness maintaining optimum performance of the nervous system

Jatamansi is a relaxing plant, effectiveness for mental health. It is used in various Ayurvedic formulations as a potent ingredient. It has been shown effective in maintaining a restful sleep and with many menopausal symptoms

Pippali is a powerful stimulant for both the digestive and the respiratory systems and has a rejuvenating effect on lungs. It plays an important role in release of metabolic heat energy. This effect is the result of increased thyroid hormone level in the body. Pippali a typical Ayurvedic complementary component whose benefit is to increase the bioavailability and enhance absorption of the other active ingredients

Piper nigrum L. Maricha, Black pepper

The black pepper is one of the most important spices which is widely used to amplify the body's ability to absorb nutrients contained in the food and aid the digestive process

Bergenia ligulata Wall Pasanavheda

It has the unique property like diuretic action with optimum urinary tract health. This important drug supports bladder by acting on the crystalloid-colloid balance and keeping calcium salts in solution

Terminalia chebula Retz. Haritaki

Haritaki is a safe and effective purgative, expectorant and tonic. It is an important ingredient of the classical Ayurvedic formulation "Triphala" which has a combination of three fruits. Tiphalpha is an important Ayurvedic medicine which promotes health through successive steps of purification and detoxification. It is known to have strong antimutagenic activity, because of its very rich content vitamin $\mathrm{C}$

Tinospora cordifolia Miers Guduchi Guduchi is a rich source of natural vitamin $\mathrm{C}$ and effective in inhibiting the growth of bacteria and in building up the immune resistance and has immuneboosting ability. Use of this plant increases white blood cells the killing ability 
Bot. Res. J., 12 (1-4): 1-30, 2019

Table 3: Continue

\begin{tabular}{lll}
\hline Plant name & Common name & Uses \\
Withania somnifera (L.) Dunal & Ashwagandha & $\begin{array}{l}\text { of macrophages, the immune cells responsible for fighting invaders } \\
\text { In Ayurvedic medicines Ashwagandha holds a place similar to Ginseng in } \\
\text { traditional Chinese medicinal therapies. It is also called the "Indian Ginseng." } \\
\text { It has been used for thousands of years as a popular remedy in Ayurvedic systems } \\
\text { for many conditions. It is one of the best health tonics and restorative agents that } \\
\text { have been used to treat general debility }\end{array}$ \\
& $\begin{array}{l}\text { Ginger is considered an adjuvant in many Ayurvedic formulas in which it } \\
\text { enhances absorption and prevents gastrointestinal side effects. It is a very common } \\
\text { spice which is used in Ayurvedic medicine to improve digestion and to prevent } \\
\text { nausea. These properties help bowel movements and relax the muscles which } \\
\text { control the digestive system }\end{array}$ \\
\hline
\end{tabular}

Table 4: Some important herbal formulations frequently used in traditional Ayurvedic system in India (Anonymous, 2016a-c)

\begin{tabular}{|c|c|c|}
\hline Diseases & Formulation's ingredients/ratio & Dose/method of use \\
\hline$\overline{\text { Anemia }}$ & $\begin{array}{l}\text { Asparagus racemosus (roots) } 20 \% \\
\text { Withania somnifera (roots) } 20 \% \\
\text { Phyllanthus emblica (fruits) } 15 \% \\
\text { P. amarus (leaves) } 10 \% \\
\text { Tephrosia purpurea (leaves) } 10 \% \\
\text { Plumbago zeylanica (roots) } 5 \% \\
\text { Glycyrrhiza glabra (roots) } 15 \% \\
\text { Piper longum (fruits) 5\% }\end{array}$ & $4 \mathrm{~g}$ of powder is given to the patient, twice daily with water \\
\hline Asthma/bronchitis & $\begin{array}{l}\text { Solanum xanthocarpum (whole plant) } 25 \% \\
\text { Piper longum (fruits) } 10 \% \\
\text { Adhatoda vasica (leaves) } 25 \% \\
\text { Zingiber officinale (roots) } 10 \% \\
\text { Curcuma zedoaria (roots) } 10 \% \\
\text { Ocimum sanctum (leaves) } 10 \% \\
\text { Phyllanthus emblica (fruits) } 10 \%\end{array}$ & $\begin{array}{l}4 \mathrm{~g} \text { (one teaspoonful) of mixed powder given to the patient, } \\
\text { twice a day (morning and at bedtime) with water }\end{array}$ \\
\hline Arthritis & $\begin{array}{l}\text { Piper longum (fruits) } 10 \% \\
\text { xanthocarpum (whole plant) } 15 \% \\
\text { Withania somnifera (roots) } 10 \% \\
\text { Terminalia chebula (fruits) } 10 \% \\
\text { bellerica } \text { (fruits) } 10 \% \\
\text { Curcuma zedoaria (roots) } 15 \% \\
\text { Phyllanthus emblica (fruits) } 15 \% \\
\text { Ricinus communis (roots) } 15 \%\end{array}$ & $\begin{array}{l}4 \mathrm{~g} \text { of mixed powder should be given to the patient, twice daily } \\
\text { (morning and evening, one hour before meals) with ginger juice } \\
\text { for rheumatic problems }\end{array}$ \\
\hline Blood circulation & $\begin{array}{l}\text { Zingiber officinale (roots) 20\% } \\
\text { Piper longum (roots) } 10 \% \\
\text { Withania somnifera (roots) } 10 \% \\
\text { Phyllanthus emblica (fruits) } 10 \% \\
\text { Curcuma longa (roots) } 10 \% \\
\text { Terminalia bellerica (fruits) } 10 \% \\
\text { T. chebula (fruits) } 10 \% \\
\text { Ocimum sanctum (leaves) } 10 \% \\
\text { Tephrosia purpurea (leaves) } 10 \%\end{array}$ & $4 \mathrm{~g}$ of mixed powder is given to the patient, twice daily with water \\
\hline Cancer & $\begin{array}{l}\text { Azadirachta indica (bark) } 20 \% \\
\text { Bauhinia variegata (bark) } 15 \% \\
\text { Crataeva nurvala (bark) } 15 \% \\
\text { Terminalia chebula (fruits) } 15 \% \\
\text { T. bellerica (fruits) } 10 \% \\
\text { Holarrhena antidysenterica (bark) } 10 \% \\
\text { Tinospora cordifolia (stems) } 15 \%\end{array}$ & $\begin{array}{l}4 \mathrm{~g} \text { of mixed powder should be given to the patient, twice a day } \\
\text { (morning and night) with lukewarm honey for cancer cure }\end{array}$ \\
\hline Chronic constipation & $\begin{array}{l}\text { Holarrhena antidysenterica (bark) } 10 \% \\
\text { Plumbago ovata (husk) } 20 \% \\
\text { Terminalia bellerica (fruits) } 10 \% \\
\text { T. chebula (fruits) } 15 \% \\
\text { Phyllanthus emblica (fruits) } 15 \% \\
\text { Cassia angustifolia (leaves) } 20 \% \\
\text { Glycyrrhiza glabra (roots) } 10 \%\end{array}$ & $\begin{array}{l}4 \mathrm{~g} \text { of mixed powder is given to the patient, at night before going } \\
\text { to bed, with water }\end{array}$ \\
\hline Chronic fever & $\begin{array}{l}\text { Tinospora cordifolia (stems) } 15 \% \\
\text { Ocimum sanctum (leaves) } 15 \% \\
\text { Adhatoda vasica (leaves) } 15 \% \\
\text { Azadirachta indica (leaves) } 15 \% \\
\text { Holarrhena antidysenterica (bark) } 10 \% \\
\text { Piper longum (fruits) } 10 \% \\
\text { Zingiber officinale (roots) } 10 \%\end{array}$ & $\begin{array}{l}4 \mathrm{~g} \text { of mixed powder is given to the patient, twice daily before } \\
\text { meals with water }\end{array}$ \\
\hline
\end{tabular}


Bot. Res. J., 12 (1-4): 1-30, 2019

Table 4: Continue

\begin{tabular}{|c|c|c|}
\hline Diseases & Formulation's ingredients/ratio & Dose/method of use \\
\hline Cough & $\begin{array}{l}\text { Terminalia bellerica (fruits) } 10 \% \\
\text { Phyllanthus emblica (fruits) } 25 \% \\
\text { Adhatoda vasica (leaves) } 20 \% \\
\text { Ocimum sanctum (leaves) } 10 \% \\
\text { Piper longum (fruits) } 10 \% \\
\text { Zingiber officinale (roots) } 10 \% \\
\text { Glycyrrhiza glabra (roots) } 15 \% \\
\text { Solanum xanthocarpum (whole plant) } 10 \%\end{array}$ & $\begin{array}{l}3 \mathrm{~g} \text { of mixed powder should be given to the patient twice daily } \\
\text { (morning and at night before going to bed) with lukewarm mixed } \\
\text { with honey to cure cold }\end{array}$ \\
\hline Cysts & $\begin{array}{l}\text { Terminalia chebula (fruits) } 20 \% \\
\text { Azadirachta indica (bark) } 20 \% \\
\text { Holarrhena antidysenterica } \text { (bark) } 10 \% \\
\text { Terminalia bellerica (fruits) } 10 \% \\
\text { Withania somnifera (roots) } 20 \% \\
\text { Tinospora cordifolia (stems) } 20 \%\end{array}$ & $\begin{array}{l}4 \mathrm{~g} \text { of mixed (one teaspoonful) powder is given to the patient, } \\
\text { twice a day (morning and evening) with water }\end{array}$ \\
\hline Cysts & $\begin{array}{l}\text { Terminalia chebula (fruits) } 20 \% \\
\text { Azadirachta indica (bark) } 20 \% \\
\text { Holarrhena antidysenterica (bark) } 10 \% \\
\text { Terminalia bellerica (fruits) } 10 \% \\
\text { Withania somnifera (roots) } 20 \% \\
\text { Tinospora cordifolia (stems) } 20 \%\end{array}$ & $\begin{array}{l}4 \mathrm{~g} \text { of mixed (one teaspoonful) powder is given to the patient, } \\
\text { twice a day (morning and evening) with water }\end{array}$ \\
\hline Dental diseases & $\begin{array}{l}\text { Azadirachta indica (leaves) } 15 \% \\
\text { A. arabia (bark) } 15 \% \\
\text { Areca catechu (bark) } 15 \% \\
\text { Achyranthes aspera (leaves) } 10 \% \\
\text { Ficus benghalensis (bark) } 15 \% \\
\text { Quercus infectoria (fruits) } 15 \% \\
\text { Symplocos racemosa (bark) } 15 \%\end{array}$ & $\begin{array}{l}\text { The powder is applied to the gums and teeth, two times a day. } \\
\text { Additionally a gargle of the decoction ( } 3 \text { gm of powder mixed in } \\
150 \mathrm{~mL} \text { of water) }\end{array}$ \\
\hline Diarrhoea & $\begin{array}{l}\text { Holarrhena antidysenterica (bark) } 25 \% \\
\text { Aegle marmelos (fruits) } 25 \% \\
\text { Zingiber officinale (roots) } 10 \% \\
\text { Terminalia chebula (fruits) } 10 \% \\
\text { Cyperus rotundus (roots) } 10 \% \\
\text { Syzygium cumini (seeds) } 10 \% \\
\text { Phyllanthus emblica (fruits) } 10 \%\end{array}$ & $\begin{array}{l}3 \mathrm{~g} \text { of mixed powder is given to the patient, three times a day, } \\
\text { with curd for dysentery and diarrhoea }\end{array}$ \\
\hline Dislocation of bones & $\begin{array}{l}\text { Asparagus racemosus (roots) } 15 \% \\
\text { Withania somnifera (roots) } 15 \% \\
\text { Azadirachta arabica (bark) } 20 \% \\
\text { Terminalia arjuna (bark) } 20 \% \\
\text { T. chebula (fruits) } 10 \% \\
\text { T. bellerica (fruits) } 10 \% \\
\text { Phyllanthus emblica (fruits) } 10 \%\end{array}$ & $\begin{array}{l}3 \mathrm{~g} \text { of mixed powder is given to the patient, twice a day with water } \\
\text { for dislocation of bones and fractures }\end{array}$ \\
\hline Diabetes & $\begin{array}{l}\text { Gymnema sylvestre (leaves) } 30 \% \\
\text { Tinospora cordifolia (stems) } 15 \% \\
\text { Azadirachta indica (leaves) } 10 \% \\
\text { Phyllanthus emblica (fruits) } 20 \% \\
\text { Curcuma longa (roots) } 10 \% \\
\text { Aegle marmelos (leaves) } 15 \%\end{array}$ & $\begin{array}{l}4 \mathrm{~g} \text { of mixed powder should be given to the patient, twice a day } \\
\text { with water }\end{array}$ \\
\hline Fistula & $\begin{array}{l}\text { Glycyrrhiza glabra (roots) } 20 \% \\
\text { Terminalia chebula (fruits) } 20 \% \\
\text { T. bellerica (fruits) } 15 \% \\
\text { Tinospora cordifolia (stems) } 15 \% \\
\text { Azadirachta indica (leaves) } 15 \% \\
\text { Withania somnifera (roots) } 15 \%\end{array}$ & $\begin{array}{l}3 \mathrm{~g} \text { of mixed powder should be given to the patient, twice daily } \\
\text { with water to treat fistula }\end{array}$ \\
\hline Female sterility & $\begin{array}{l}\text { Asparagus racemosus (roots) 20\% } \\
\text { Withania somnifera (roots) } 20 \% \\
\text { Glycyrrhiza glabra (roots) } 20 \% \\
\text { Phyllanthus emblica (fruits) } 10 \% \\
\text { Ficus glomerata (bark) } 10 \% \\
\text { F. religiosa (bark) } 10 \%\end{array}$ & $\begin{array}{l}3 \mathrm{~g} \text { of mixed powder is given to the patient twice daily, half an } \\
\text { hour before meals with milk }\end{array}$ \\
\hline General health tonic & $\begin{array}{l}\text { Withania somnifera (roots) } 20 \% \\
\text { Asparagus racemosus (roots) } 10 \% \\
\text { Glycyrrhiza glabra (roots) } 10 \% \\
\text { Tribulus terrestris (fruits) } 10 \% \\
\text { Phyllanthus emblica (fruits) } 15 \% \\
\text { Terminalia arjuna (bark) } 15 \% \\
\text { Centella asiatica (leaves) } 10 \%\end{array}$ & $\begin{array}{l}4 \mathrm{~g} \text { of powder is given to the patient, twice daily (morning and } \\
\text { evening) with milk }\end{array}$ \\
\hline Gastritis & Zingiber officinale (roots) $10 \%$ & $4 \mathrm{~g}$ of (one teaspoonful) mixed powder is given to the patient \\
\hline
\end{tabular}


Bot. Res. J., 12 (1-4): 1-30, 2019

Table 4: Continue

\begin{tabular}{|c|c|c|}
\hline Diseases & Formulation's ingredients/ratio & Dose/method of use \\
\hline & $\begin{array}{l}\text { Piper longum (fruits) } 10 \% \\
\text { Mentha piperita (leaves) } 10 \% \\
\text { Terminalia chebula (fruits) } 15 \% \\
\text { T. bellerica (fruits) } 15 \% \\
\text { Phyllanthus emblica (fruits) } 15 \% \\
\text { Plumbago zeylanica (roots) } 10 \% \\
\text { Tinospora cordifolia (stems) } 15 \%\end{array}$ & twice daily, half an hour before meals with water \\
\hline Hair problems & $\begin{array}{l}\text { Eclipta alba (leaves) } 15 \% \\
\text { Centella asiatica (leaves) } 15 \% \\
\text { Terminalia chebula (fruits) } 10 \% \\
\text { T. bellerica (fruits) } 10 \% \\
\text { Phyllanthus emblica (fruits) } 15 \% \\
\text { Glycyrrhiza glabra (roots) } 15 \% \\
\text { Tinospora cordifolia (stems) } 10 \% \\
\text { Tribulus terrestris (fruits) } 10 \%\end{array}$ & $\begin{array}{l}4 \mathrm{~g} \text { of mixed powder is given to the patient, twice a daily with } \\
\text { honey }\end{array}$ \\
\hline High blood pressure & $\begin{array}{l}\text { Terminalia arjuna (bark) } 35 \% \\
\text { T. chebula (fruits) } 15 \% \\
\text { Asparagus racemosus (roots) } 15 \% \\
\text { Zingiber officinale (roots) } 10 \% \\
\text { Withania somnifera (roots) } 25 \%\end{array}$ & $\begin{array}{l}4 \mathrm{~g} \text { of powder is given to the patient, twice a day (morning and } \\
\text { night) with honey }\end{array}$ \\
\hline Heart tonic & $\begin{array}{l}\text { Withania somnifera (roots) } 10 \% \\
\text { Terminalia arjuna (bark) } 30 \% \\
\text { T. bellerica (fruits) } 10 \% \\
\text { T. chebula (fruits) } 10 \% \\
\text { Cyperus rotundus (roots) } 10 \% \\
\text { Phyllanthus emblica (fruits) } 10 \% \\
\text { Ocimum sanctum (leaves) } 10 \%\end{array}$ & $3 \mathrm{~g}$ of mixed powder is given to the patient, twice a day with water \\
\hline Intestinal worms & $\begin{array}{l}\text { Holarrhena antidysenterica (bark) 10\% } \\
\text { Mentha piperita (leaves) } 10 \% \\
\text { Tinospora cordifolia (stems) } 20 \% \\
\text { Butea monosperma (seeds) } 20 \% \\
\text { Azadirachta indica (leaves) } 10 \% \\
\text { Phyllanthus emblica (fruits) } 20 \% \\
\text { Tribulus terrestris (fruits) } 10 \%\end{array}$ & $\begin{array}{l}3 \mathrm{~g} \text { of mixed powder is given to the patient, twice daily (morning } \\
\text { and night) with water }\end{array}$ \\
\hline Epilepsy & $\begin{array}{l}\text { Centella asiatica (leaves) } 30 \% \\
\text { Withania somnifera (roots) } 20 \% \\
\text { Tribulus terrestris (fruits) } 15 \% \\
\text { Piper longum (roots) } 10 \% \\
\text { Achyranthes aspera (leaves) } 15 \% \\
\text { Plumbago zeylanica (roots) } 10 \%\end{array}$ & $\begin{array}{l}3 \mathrm{~g} \text { mixed powder is given to the patient, twice daily (morning } \\
\text { and evening) with fruit juice to treat Hysteria }\end{array}$ \\
\hline Leucorrhoea & $\begin{array}{l}\text { Symplocos racemosa (bark) } 35 \% \\
\text { Asparagus racemosus (roots) } 15 \% \\
\text { Adhatoda vasica (leaves) } 10 \% \\
\text { Aegle marmelos (fruits) } 10 \% \\
\text { Phyllanthus emblica (fruits) } 10 \% \\
\text { Azadirachta indica (bark) } 10 \%\end{array}$ & $3 \mathrm{~g}$ of mixed powder is given to the patient, twice daily with water \\
\hline Leucoderma & $\begin{array}{l}\text { Psoralea corylifolia (seeds) 20\% } \\
\text { Terminalia chebula (fruits) } 10 \% \\
\text { Phyllanthus emblica (fruits) } 20 \% \\
\text { Azadirachta indica (bark) } 20 \% \\
\text { Areca catechu (bark) } 10 \% \\
\text { Tinospora cordifolia (stems) } 10 \% \\
\text { Eclipta alba (leaves) } 10 \%\end{array}$ & $\begin{array}{l}3 \mathrm{~g} \text { of mixed powder should be given to the patient, twice a day } \\
\text { before meals with water }\end{array}$ \\
\hline Liver tonic & $\begin{array}{l}\text { Holarrhena antidysenterica (bark) } 10 \% \\
\text { Eclipta alba (leaves) } 20 \% \\
\text { Tephrosia purpurea (leaves) } 20 \% \\
\text { Tinospora cordifolia (stems) } 10 \% \\
\text { Azadirachta indica (bark) } 10 \% \\
\text { Phyllanthus amarus (whole plant) } 20 \% \\
\text { Plumbago zeylanica (roots) } 10 \%\end{array}$ & $\begin{array}{l}4 \mathrm{~g} \text { of mixed powder is given to the patient twice daily, half an } \\
\text { hour before meals with water }\end{array}$ \\
\hline Lack of appetite & $\begin{array}{l}\text { Zingiber officinale (roots) } 10 \% \\
\text { Piper longum (fruits) } 10 \% \\
\text { Phyllanthus emblica (fruits) } 30 \% \\
\text { Terminalia chebula (fruits) } 15 \% \\
\text { Tinospora cordifolia (stems) } 15 \% \\
\text { Cassia angustifolia (leaves) } 10 \% \\
\text { Mentha piperita (leaves) } 10 \% \\
\end{array}$ & $\begin{array}{l}4 \mathrm{~g} \text { of mixed powder is given to the patient, two times a day after } \\
\text { meals with water for indigestion }\end{array}$ \\
\hline
\end{tabular}


Bot. Res. J., 12 (1-4): 1-30, 2019

Table 4: Continue

\begin{tabular}{|c|c|c|}
\hline Diseases & Formulation's ingredients/ratio & Dose/method of use \\
\hline Male sterility & $\begin{array}{l}\text { Withania somnifera (roots) } 15 \% \\
\text { Mucuna pruriens (seeds) } 25 \% \\
\text { Tribulus terrestris (fruits) } 20 \% \\
\text { Glycyrrhiza glabra (roots) } 10 \% \\
\text { Terminalia arjuna (bark) } 10 \% \\
\text { Phyllanthus emblica (fruits) } 10 \% \\
\text { Zingiber officinale (roots) } 5 \% \\
\text { Piper longum (fruits) } 5 \%\end{array}$ & $\begin{array}{l}4 \text { gm of mixed powder is given to the patient, twice a day with } \\
\text { honey }\end{array}$ \\
\hline Migraine & $\begin{array}{l}\text { Curcuma longa (roots) 15\% } \\
\text { Glycyrrhiza glabra (roots) } 15 \% \\
\text { Azadirachta indica (bark) 15\% } \\
\text { Tinospora cordifolia (stems) } 15 \% \\
\text { Terminalia chebula (fruits) } 10 \% \\
\text { Ocimum sanctum (leaves) } 15 \% \\
\text { Eclipta alba (leaves) } 15 \%\end{array}$ & $\begin{array}{l}4 \mathrm{~g} \text { of mixed powder is given to the patient, twice a day with } \\
\text { honey }\end{array}$ \\
\hline Obesity & Terminalia chebula (fruits) $15 \%$ & $4 \mathrm{~g}$ of powder is given to the patient, twice a day with warm water \\
\hline
\end{tabular}

Terminalia bellerica (fruits) 15\%

Phyllanthus emblica (fruits) $10 \%$

Crataeva nurvala (bark) $25 \%$

Tribulus terrestris (fruits) 25\%

Zingiber officinale (roots) $10 \%$

Paralysis

Curcuma zedoaria (roots) $20 \%$

Withania somnifera (roots) $20 \%$

Tribulus terrestris (fruits) 20\%

Zingiber officinale (roots) $20 \%$

Piper longum (fruits) 5\%

Crataeva nurvala (leaves) 10\%

Plumbago zeylanica (roots) 5\%

Prostate enlargement Tinospora cordifolia (stems) 15

Tribulus terrestris (fruits) $15 \%$

Phyllanthus emblica (fruits) $15 \%$

Zingiber officinale (roots) $10 \%$

Butea monosperma (seeds) $10 \%$

Adhatoda vasica (leaves) $5 \%$

Terminalia chebula (fruits) 10\%

T. bellerica (fruits) $10 \%$

Glycyrrhiza glabra (roots) 10\%

Piles

Eclipta alba (leaves) 35

Terminalia chebula (fruits) 15\%

Terminalia bellerica (fruits) $10 \%$

Phyllanthus emblica (fruits) $10 \%$

Adhatoda vasica (leaves) $10 \%$

Plumbago zeylanica (roots) 5\%

Piper longum (fruits) $5 \%$

Aegle marmelos (fruits) $10 \%$

Sleeplessness Withania somnifera (roots) $20 \%$

Centella asiatica (leaves) $30 \%$

Piper longum (roots) 20\%

Glycyrrhiza glabra (roots) $10 \%$

Terminalia bellerica (fruits) $10 \%$

Skin diseases

Cyperus rotundus (roots) $10 \%$

Tinospora cordifolia (stems) 20\%

Azadirachta indica (bark) $20 \%$

Terminalia chebula (fruits) $10 \%$

T. bellerica (fruits) $10 \%$

Curcuma longa (roots) $10 \%$

Phyllanthus emblica (fruits) $10 \%$

Centella asiatica (leaves) $10 \%$

Sexual debility Withania somnifera (roots) $10 \%$

Mucuna pruriens (seeds) $20 \%$

Asparagus racemosus (roots) $10 \%$

Sida cordifolia (seeds) $10 \%$

Tribulus terrestris (fruits) $20 \%$

Glycyrrhiza glabra (roots) $10 \%$

Throat diseases Glycyrrhiza glabra (roots) $30 \%$

Terminalia chebula (fruits) $10 \%$

$3 \mathrm{~g}$ of mixed powder is given to the patient, three times a day with honey

$4 \mathrm{~g}$ of mixed powder is given to the patient twice a day, morning and evening before meals with water

$4 \mathrm{~g}$ of mixed powder is given to the patient, twice daily (morning and at bedtime) with water

$3 \mathrm{~g}$ mixed powder is given to the patient, at night before going to bed, with milk

$3 \mathrm{~g}$ of powder is given to the patient, twice a day before meals with water to cure allergy problems

About $4 \mathrm{gm}$ of mixed powder should be given to the patient, twice daily (morning and at night before going to bed) with milk

$4 \mathrm{~g}$ of mixed powder is given to the patient twice daily, morning and at bedtime with honey 
Table 4: Continue

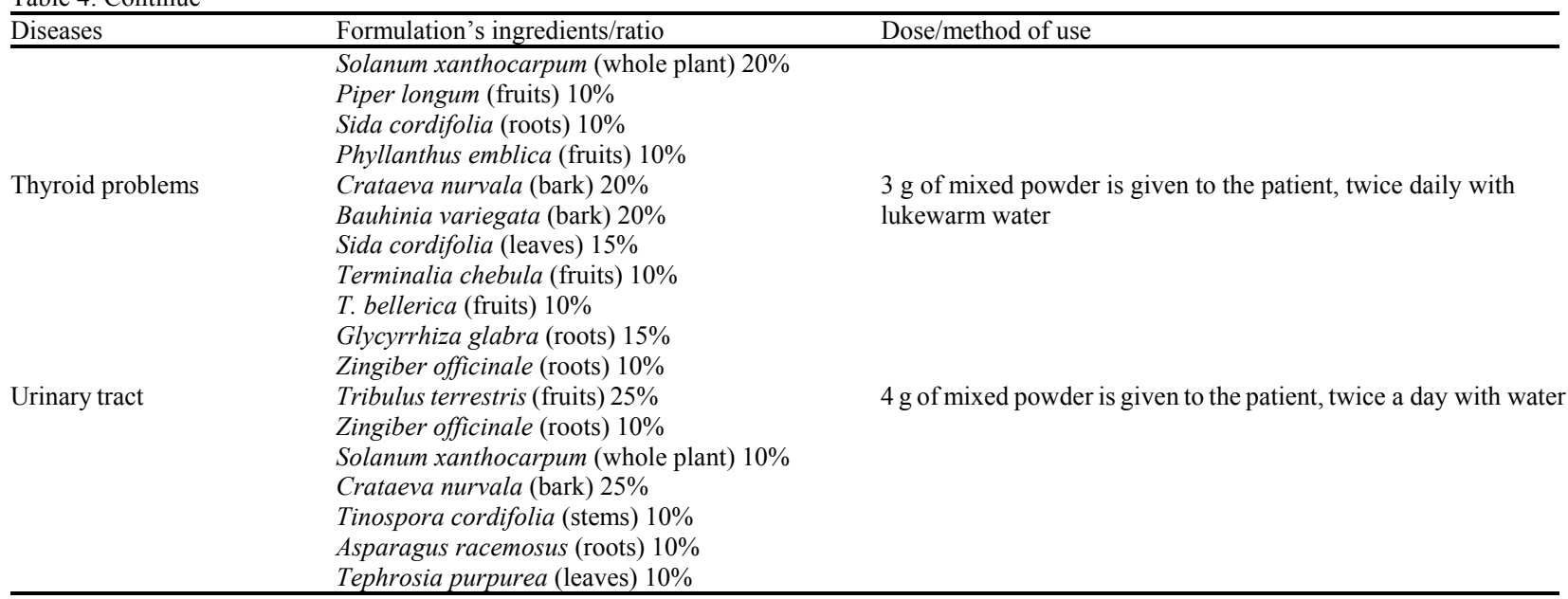

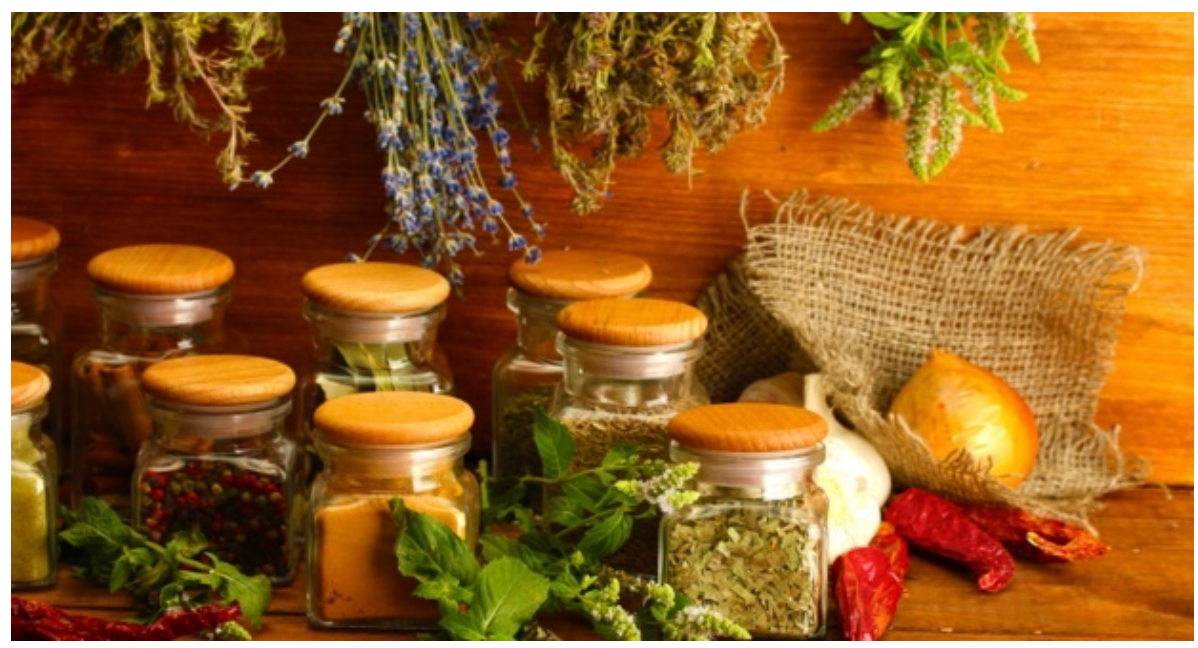

Fig. 4: Traditional herbs in use

and perhaps elsewhere in the world. Safety is critical and requires better chains of custody and product characterization that exists at present for these products, particularly those involving global markets. Efficacy that is that the health promotion claims for the product are true and not misleading is also critical. Demonstrating efficacy requires clinical studies with well defined products and rigorous experimental designs and the studies must be replicable. To that end, many publishers now require that submitted manuscripts comply with established guidelines for the reporting of clinical trial results (e.g., Consort guidelines) while funders require demonstration of product integrity by applicants (Anonymous, 2018a-c; Sebastian et al., 2017). Finally, there are issues of personal choice and values, sometimes involving the efficacy of supplements as complementary and alternative therapies that are part of a larger philosophical or religious world views and systems. These must be accommodated without abandoning safety.
Both basic and more applied challenges will continue well into the future. Much remains to be learned about the effects of bioactive constituents such as flavonoids in foods and dietary supplements on health outcomes as many recent papers in Nutrients and elsewhere indicate (Dwyer and Peterson, 2013; Gonzalez-Sarrias et al., 2017; Kim et al., 2016). More and better biomarkers need to be developed and their associations with health outcomes clarified (Kuhman et al., 2015 ). Supplements intended to enhance sports performance (Costello et al., 2016) botanicals used for disease treatment and those ingredients thought to slow aging (Davis, 2016) all require identification of valid biomarkers of efficacy as well as of exposure. The role of supplements and the gut microbiome also must be explored for its associations with common diseases and conditions (Perez-Cano and Castell, $2016 \mathrm{a}$, b). The associations between supplement ingredients and health outcomes in chronic degenerative disease must be clarified (Gaine et al., 2013; Dwyer et al., 
2007; Dwyer et al., 2017; Chamcheu et al., 2018; Perez-Cano and Castell, 2016a, b; Wardenaar et al., 2017). High risk groups need more attention certain subgroups within the population such as athletes consume very high amounts of some supplements and it is important to monitor them to prevent adverse outcomes and study the effects if any on athletic performance (Chiba et al., 2015). Others use supplements in the hope that they will improve cognitive performance (Costello et al., 2016). Those who practice polypharmacy with prescription, non-prescription drugs and dietary supplements represent another high-risk group and interventions to limit the potential for adverse events are needed (Chiba et al., 2014; Taylor and Yetley, 2008). Collaborations among scientists in many countries are needed to drive supplement science forward. Irrespective of the type of health product, high quality science is fundamental to the success of any regulatory framework. Assessments of the safety, quality and efficacy of nutrients and other bioactives are needed to provide the scientific information that regulators need. As mentioned earlier, the nature and diversity of the sector means that regulators face a number of very specific challenges for these low risk products. These include evaluating traditional evidence, dealing with products that contain multiple bio-actives and addressing the growing challenges of ensuring product quality. It is critical that scientists and regulators work together and learn from each other in both identifying issues and developing ways in which they can be addressed. Although regulatory challenges must be met at the national level, there must be due regard paid to the fact that national regulatory decisions about supplements have global implications (Taylor and Yetley, 2008; Yetley, 2007).

Epilogue: If the situation prevailing in this sector is analyzed taking into consideration different aspects it becomes clear that there is a perceptible trend towards increased usage of drugs used in Indian Traditional Systems, especially those which are based on herbal products not only in India but in different parts of the world. However, one of the basic problems that still remained to be solved is related to proving efficacy of the products used in these systems on the basis of controlled clinical trial and complementary pharmacological studies. It is difficult to ensure consistency in the results and components in the products. This is traced mainly to lack of standardization of the inputs used and the process adopted for preparation of the formulations. Government of India has taken these aspects in to consideration and has initiated many projects for standardization of single and compound formulations along with standardization of operating procedures for important formulations. Though standardization is very difficult it is not an un-attainable goal. Science is vital in regulatory settings and there is no reason that science and regulation should be incompatible. The challenges in supplement science and its regulation provide new opportunities for scientists and regulators to work together both nationally and internationally to learn from each other and to cooperate and when appropriate harmonize approaches to improve the public health.

\section{CONCLUSION}

This study summarizes some of the challenges in supplement science and provides a case study of research at the Office of Dietary Supplements at the National Institutes of Health, USA, along with some resources it has developed that are available to all scientists. It includes examples of some of the regulatory challenges faced and some resources for those who wish to learn more about them.

\section{ACKNOWLEDGEMENT}

It's a great honor and gratitude to be pharmacists in research and education process. All pharmacists, officials, journalists, magazine analysts and associates that I met in this purpose, were very kind and helpful. I'm thankful to Dr. Choudhury Mahmood Hasan, Professor, Department of Pharmaceutical Chemistry, Faculty of Pharmacy, University of Dhaka for his precious time to review my article and given their thoughtful suggestions. I'm also grateful to seminar library of Faculty of Pharmacy, University of Dhaka and BANSDOC Library, Bangladesh for providing me books, journal and newsletters. A portion of this research is long been lectured as course material. So, it is very much helpful for me to deliver better than before as many more things are studied.

\section{REFRENCES}

Ahluwalia, N., J. Dwyer, A. Terry, A. Moshfegh and C. Johnson, 2016. Update on NHANES dietary data: Focus on collection, release, analytical considerations and uses to inform public policy. Adv. Nutr., 7: 121-134.

Anonymous, 2004. Herbal medicinal products. European Commission, Brussels, Belgium. https://ec.europa. eu/health/human-use/herbal-medicines_en.

Anonymous, 2010. Natural and non-prescription health products. Government of Canada, Canada. https://www.canada.ca/en/health-canada/services/dr ugs-health-products/natural-non-prescription.html

Anonymous, 2016a. Category specific guidance for temporary marketing authorization: Supplemented food. Government of Canada, Canada. https:// www.canada.ca/en/health-canada/services/food-nut rition/legislation-guidelines/guidance-documents/ca tegory-specific-guidance-temporary-marketing-auth orization-supplemented-food.html. 
Anonymous, 2016b. Consulting Canadians on the regulation of self-care products in Canada. Government of Canada, Canada. https://www. canada.ca/en/health-canada/programs/consultation-r egulation-self-care-products/consulting-canadians-r egulation-self-care-products-canada.html.

Anonymous, 2016c. NCCIH policy: Natural product integrity. National Center for Complementary and Integrative Health (NCCIH), Bethesda, Maryland. https://nccih.nih.gov/research/policies/naturalprodu ct.htm.

Anonymous, 2017a. ASEAN harmonization of traditional medicines and health supplements. Health Sciences Authority, Singapore. https:/www.hsa.gov.sg/ content/hsa/en/Health_Products_Regulation/Compl ementary_Health_Products/Overview/ASEAN_Har monization_of_Traditional_Medicines_and_Health Supplements.h.html

Anonymous, 2017b. Complementary medicine interface issues. Therapeutic Goods Administration, Australia. https://www.tga.gov.au/complementary-medicine-i nterface-issues

Anonymous, 2017c. Exposure drafts: Therapeutic goods amendment (2017 Measures No. 1) bill 2017 and therapeutic goods (Charges) amendment bill 2017. Therapeutic Goods Administration, Australia. https://www.tga.gov.au/consultation/consultation-e xposure-drafts-2017

Anonymous, 2017d. Monograph: Melatonin-oral. Health Canada, Canada.

Anonymous, 2018a. Australian Regulatory Guidelines for Complementary Medicines (ARGCM). Therapeutic Goods Administration, Australia. https:// www.tga.gov.au/publication/australian-regulatory-g uidelines-complementary-medicines-argcm

Anonymous, 2018b. Enhancing reproducibility through rigor and transparency. National Institutes of Health (NIH), Office of Extramural Research, Bethesda, Maryland. https://grants. nih.gov/policy/reproducibility/index.htm

Anonymous, 2018c. The poisons standard (the SUSMP). Therapeutic Goods Administration, Australian. https://www.tga.gov.au/publication/poisons-standar d-susmp

Anonymous, 2019. International Regulatory Cooperation for Herbal medicines (IRCH). World Health Organization, Geneva, Switzerland. https:// www.who.int/medicines/areas/traditional/irch/en/

Avigan, M.I., R.P. Mozersky and L.B. Seeff, 2016. Scientific and regulatory perspectives in herbal and dietary supplement associated hepatotoxicity in the United States. Intl. J. Mol. Sci., 17: 1-30.

Bailey, L.B., P.J. Stover, H. McNulty, M.F. Fenech and J.F. Gregory III et al., 2015. Biomarkers of nutrition for development-folate review. J. Nutr., 145: $1636 \mathrm{~S}-1680 \mathrm{~S}$.
Bailey, R.L., J.J. Gahche, P.E. Miller, P.R. Thomas and J.T. Dwyer, 2013. Why US adults use dietary supplements. JAMA Internal Med., 173: 355-361.

Bailey, R.L., J.J. Gahche, P.E. Miller, P.R. Thomas and J.T. Dwyer, 2013. Why US children use dietary supplements. Pediatr. Res., 74: 737-741.

Balentine, D.A., J.T. Dwyer, J.W. Erdman Jr, M.G. Ferruzzi and P.C. Gaine et al., 2015. Recommendations on reporting requirements for flavonoids in research. Am. J. Clin. Nutr., 101: 1113-1125.

Balk, E.M. and A.H. Lichtenstein, 2017. Omega-3 fatty acids and cardiovascular disease: Summary of the 2016 agency of healthcare research and quality evidence review. Nutrients, 9: 1-13.

Berner, L.A., D.R. Keast, R.L. Bailey and J.T. Dwyer, 2014. Fortified foods are major contributors to nutrient intakes in diets of US children and adolescents. J. Acad. Nutr. Diet., 114: 1009-1022.

Betz, J.M. and M. Hardy, 2014. Evaluating the botanical dietary supplement literature. HerbalGram, 101: 58-67.

Betz, J.M. and M.L. Hardy, 2010. Evaluating the Botanic Dietary Supplement Literature. In: The H.E.R.B.A.L. Guide: Dietary Supplement Resources for the Clinician, Bonakdar, R.A. (Ed.). Lippincott Williams and Wilkins, Philadelphia, Pennsylvania, USA., ISBN:978-0-7817-8268-5, pp: 175-184.

Betz, J.M., K.D. Fisher, L.G. Saldanha and P.M. Coates, 2007. The NIH analytical methods and reference materials program for dietary supplements. Anal. Bioanal. Chem., 389: 19-25.

Betz, J.M., P.N. Brown and M.C. Roman, 2011. Accuracy, precision and reliability of chemical measurements in natural products research. Fitoterapia, 82: 44-52.

Blumberg, J.B., B.B. Frei, V.L. Fulgoni III, C.M. Weaver and S. Zeisel, 2017. Impact of frequency of multi-vitamin/multi-mineral supplement intake on nutritional adequacy and nutrient deficiencies in US adults. Nutrients, 9: 1-15.

Boyles, A.L., E.A. Yetley, K.A. Thayer and P.M. Coates, 2016. Safe use of high intakes of folic acid: Research challenges and paths forward. Nutr. Rev., 74: 469-474.

Brannon, P.M. and C.L. Taylor, 2017. Iron supplementation during pregnancy and infancy: Uncertainties and implications for research and policy. Nutrients, 9: 1-17.

Brannon, P.M., C.L. Taylor and P.M. Coates, 2014. Use and applications of systematic reviews in public health nutrition. Annu. Rev. Nutr., 34: 401-419.

Branum, A.M., R. Bailey and B.J. Singer, 2013. Dietary supplement use and folate status during pregnancy in the United States. J. Nutr., 143: 486-492. 
Brooks, J.R., H. Oketch-Rabah, T.L. Dog, D.K.J. Gorecki and M.L. Barrett et al., 2016. Safety and performance benefits of Arginine supplements for military personnel: A systematic review. Nutr. Rev., 74: 708-721.

Brooks, S.P.J. and C.T. Sempos, 2017. The importance of 25-hydroxyvitamin D assay standardization and the Vitamin D standardization program. J. AOAC. Intl., 100: 1223-1224.

Brown, A.C., 2017. An overview of herb and dietary supplement efficacy, safety and government regulations in the United States with suggested improvements: Part 1 of 5 series. Food Chem. Toxicol., 107: 449-471.

Brown, A.C., 2017. Liver toxicity related to herbs and dietary supplements: Online table of case reports, Part 2 of 5 series. Food Chem. Toxicol., 107: 472-501.

Centers for Disease Control and Prevention, 2014. Second National Report on Biochemical Indicators of Diet and Nutrition in the US Population 2012. CreateSpace Independent Publishing, Scotts Valley, California?, USA., ISBN:9781499695403, Pages: 496.

Chamcheu, J.C., D.N. Syed and G.K. Whitfield, 2018. Nutraceuticals and the Skin: Roles in Health and Disease. MDPI Company, Basel, Switzerland, ISBN:978-3-03897-187-0, Pages: 224.

Chiba, T., Y. Sato, S. Suzuki and K. Umegaki, 2015. Concomitant use of dietary supplements and medicines in patients due to miscommunication with physicians in Japan. Nutrients, 7: 2947-2960.

Chiba, T., Y. Sato, T. Nakanishi, K. Yokotani and S. Suzuki et al., 2014. Inappropriate usage of dietary supplements in patients by miscommunication with physicians in Japan. Nutrients, 6: 5392-5404.

Cooper, E.L., 2005. CAM, eCAM, bioprospecting: The $21 \mathrm{st}$ century pyramid. Evidence Based Complementary Altern. Med., 2: 125-127.

Cooper, E.L., 2008. Ayurveda and eCAM: A closer connection. Evidence based Complementary Altern. Med., 5: 121-122.

Cooper, E.L., 2008. Ayurveda is embraced by eCAM. Evidence Based Complementary Altern. Med., 5: 1-2.

Costello, R.B., J.T. Dwyer and R.L. Bailey, 2016. Chromium supplements for glycemic control in type 2 diabetes: Limited evidence of effectiveness. Nutr. Rev., 74: 455-468.

Davis, C.D., 2016. The gut microbiome and its role in obesity. Nutr. Today, 51: 167-174.

De Boer, Y.S. and A.H. Sherker, 2017. Herbal and dietary supplement induced liver injury. Clin. Liver Dis., 21: 135-149.

De Toro-Martin, J., B.J. Arsenault, J.P. Despres and M.C. Vohl, 2017. Precision nutrition: A review of personalized nutritional approaches for the prevention and management of metabolic syndrome. Nutrients, 9: 1-28.
Dickinson, A., 2011. History and overview of DSHEA. Fitoterapia, 82: 5-10.

Drueke, T.B. and Z.A. Massy, 2012. Role of vitamin D in vascular calcification: Bad guy or good guy?. Nephrology Dialysis Transplant., 27: 1704-1707.

Dwyer, J., R.B. Costello and J. Merkel, 2017. Assessment of Dietary Supplements. In: Nutrition in the Prevention and Treatment of Disease, Coulston, A.M., C.J. Boushey, M.G. Rerruzai and L.M. Delahaty (Eds.). Academic Press, London, UK, pp: 49-70.

Dwyer, J.T and J. Peterson, 2013. Tea and flavonoids: where we are where to go next. Am. J. Clin. Nutr., 98: 1611S-1618S.

Dwyer, J.T., C. Woteki, R. Bailey, P. Britten and A. Carriquiry et al., 2014. Fortification: New findings and implications. Nutr. Rev., 72: 127-141.

Dwyer, J.T., J. Holden, K. Andrews, J. Roseland and C. Zhao et al., 2007. Measuring vitamins and minerals in dietary supplements for nutrition studies in the USA. Anal. Bioanal. Chem., 389: 37-46.

Dwyer, J.T., K.L. Wiemer, O. Dary, C.L. Keen and J.C. et al., 2015. Fortification and health: Challenges and opportunities. Adv. Nutr., 6: 124-131.

Dwyer, J.T., L.G. Saldanha, R.A. Bailen, R.L. Bailey and R.B. Costello et al., 2014. A free new dietary supplement label database for registered dietitian nutritionists. J. Acad. Nutr. Diet., 114: 1512-1517.

Dwyer, J.T., M.F. Picciano, J.M. Betz, K.D. Fisher and L.G. Saldanha et al., 2008. Progress in developing analytical and label-based dietary supplement databases at the NIH Office of Dietary Supplements. J. Food Compos. Anal., 21: S83-S93.

Ershow, A.G., S.A. Skeaff, J.M. Merkel and P.R. Pehrsson, 2018. Development of databases on iodine in foods and dietary supplements. Nutrients, 10: $1-20$.

Fulgoni III, V.L., D.R. Keast, R.L. Bailey and J. Dwyer, 2011. Foods, fortificants and supplements: Where do Americans get their nutrients?. J. Nutr., 141: 1847-1854.

Gagnier, J.J., H. Boon, P. Rochon, D. Moher and J. Barnes et al., 2006. Reporting randomized, controlled trials of herbal interventions: An elaborated CONSORT statement. Ann. Internal Med., 144: 364-367.

Gagnier, J.J., J. DeMelo, H. Boon and P. Rochon, 2006. Bombardier C. Quality of reporting of randomized controlled trials of herbal medicine interventions. Am. J. Med., 119: 800e1-811e11.

Gaine, P.C., D.A. Balentine, J.W. Erdman Jr, J.T. Dwyer and K.C. Ellwood et al., 2013. Are dietary bioactives ready for recommended intakes?. Adv. Nutr., 4: 539-541. 
Gardiner, P., R. Phillips and A.F. Shaughnessy, 2008. Herbal and dietary supplement-drug interactions in patients with chronic illnesses. Am. Family Physician, 77: 73-78.

Gavaghan, H., 1994. Koop may set-up new center for alternative medicine. Nat., 370: 591-591.

Ghodke, Y., K. Joshi and B. Patwardhan, 2011. Traditional medicine to modern pharmacogenomics: Ayurveda Prakriti type and CYP2C19 gene polymorphism associated with the metabolic variability. Evidence Based Complementary Altern. Med., 2011: 1-5.

Gonzalez-Sarrias, A., E. Combet, P. Pinto, P. Mena and M. Dall'Asta et al., 2017. A systematic review and meta-analysis of the effects of flavanol-containing tea, cocoa and apple products on body composition and blood lipids: Exploring the factors responsible for variability in their efficacy. Nutrients, 9: 1-28.

Gorman, U., J.C. Mathers, K.A. Grimaldi, J. Ahlgren and K. Nordstrom, 2013. Do we know enough? A scientific and ethical analysis of the basis for genetic-based personalized nutrition. Genes Nutr., 8: 373-381.

Helfand, M. and H. Balshem, 2010. AHRQ series paper 2: Principles for developing guidance: AHRQ and the effective health-care program. J. Clin. Epidemiol., 63: 484-490.

Kantor, E.D., C.D. Rehm, M. Du, E. White and E.L. Giovannucci, 2016. Trends in dietary supplement use among US adults from 1999-2012. JAMA., 316: 1464-1474.

Kim, K., T.M. Vance and O.K. Chun, 2016. Greater total antioxidant capacity from diet and supplements is associated with a less Atherogenic blood profile in U.S. adults. Nutrients, 8: 1-14.

Ko, R., T.L. Dog, D.K. Gorecki, L.R. Cantilena and R.B. Costello et al., 2014. Evidence-based evaluation of potential benefits and safety of beta-alanine supplementation for military personnel. Nutr. Rev., 72: $217-225$.

Kuhman, D.J., K.J. Joyner and R.J. Bloomer, 2015. Cognitive performance and mood following ingestion of a theacrine-containing dietary supplement, caffeine, or placebo by young men and women. Nutrients, 7: 9618-9632.

Kuszak, A.J., D.C. Hopp, J.S. Williamson, J.M. Betz and B.C. Sorkin, 2016. Approaches by the US National Institutes of Health to support rigorous scientific research on dietary supplements and natural products. Drug Test. Anal., 8: 413-417.

LaBudde, R.A. and J. Harnly, 2012. Probability of identification: A statistical model for the validation of qualitative botanical identification methods. J. AOAC. Intl., 95: 273-285.
Lichtenstein, A.H., E.A. Yetley and J. Lau, 2009. Application of systematic review methodology to the field of nutrition. MSc Thesis, Agency for Healthcare Research and Quality, Rockville, Maryland, USA.

Manson, J.E., P.M. Brannon, C.J. Rosen and C.L. Taylor, 2016. Vitamin D deficiency-is there really a pandemic?. N. Engl. J. Med., 375: 1817-1820.

Marik, P.E. and M. Flemmer, 2012. Do dietary supplements have beneficial health effects in industrialized nations: What is the evidence?. J. Parenteral Enteral Nutr., 36: 159-168.

Mashelkar, R.A., 2008. Second world Ayurveda congress (Theme: Ayurveda for the future)-inaugural address: Part III. Evidence Based Complementary Altern. Med., 5: 367-369.

Moorthy, D., M. Chung, J. Lee, W.W. Yu and J. Lau et al., 2011. Concordance between the findings of epidemiological studies and randomized trials in nutrition: An empirical evaluation and citation analysis. Master Thesis, Agency for Healthcare Research and Quality (AHRQ), Rockville, Maryland, USA.

Mudge, E.M., J.M. Betz and P.N. Brown, 2016. The importance of method selection in determining product integrity for nutrition research. Adv. Nutr., 7: 390-398.

Orhan, I.E., F.S. Senol, K. Skalicka-Wozniak, M. Georgiev and B. Sener, 2016. Adulteration and Safety Issues in Nutraceuticals and Dietary Supplements: Innocent or Risky. In: Nutraceuticals, Nanotechnology in the Agri-Food Industry, Grumezescu, A.M. (Ed.). Academic Press, Amsterdam, Netherlands, ISBN:9780128043059, pp: 153-182.

Pandey, M.M., S. Rastogi and A.K.S. Rawat, 2008. Indian herbal drug for general healthcare: An overview. Int. J. Alter. Med., Vol. 6.

Pandey, M.M., S. Rastogi and A.K.S. Rawat, 2013. Indian traditional ayurvedic system of medicine and nutritional supplementation. Evidence Based Complementary Altern. Med., 2013: 1-12.

Patwardhan, B., D. Warude, P. Pushpangadan and N. Bhatt, 2005. Ayurveda and traditional chinese medicine: A comparative overview. Evid. Based Complement Alternant. Med., 2: 465-473.

Perez-Cano, F.J. and M. Castell, 2016. Flavonoids, inflammation and immune system. Nutrients, 8: 1-4.

Perez-Cano, F.J. and M. Castell, 2016. Flavonoids, inflammation and immune system. Nutrients, Vol. 8 . 10.3390/nu8100659

Pfeiffer, C.M., D.A. Lacher, R.L. Schleicher, C.L. Johnson and E.A. Yetley, 2017. Challenges and lessons learned in generating and interpreting NHANES nutritional biomarker data. Adv. Nutr., 8: 290-307. 
Pfeiffer, C.M., J.P. Hughes, D.A. Lacher, R.L. Bailey and R.J. Berry et al., 2012. Estimation of trends in serum and RBC folate in the US population from pre-to postfortification using assay-adjusted data from the NHANES 1988-2010. J. Nutr., 142: 886-893.

Pfeiffer, C.M., M.R. Sternberg, H.C. Hamner, K.S. Crider and D.A. Lacher et al., 2016. Applying inappropriate cutoffs leads to misinterpretation of folate status in the US population. Am. J. Clin. Nutr., 104: 1607-1615.

Phinney, K.W., M. Bedner, S.S.C. Tai, V.V. Vamathevan and L.C. Sander et al., 2012. Development and certification of a standard reference material for vitamin D metabolites in human serum. Anal. Chem., 84: 956-962.

Phinney, K.W., S.S.C. Tai, M. Bedner, J.E. Camara and R.R. Chia et al., 2017. Development of an improved standard reference material for vitamin D metabolites in human serum. Anal. Chem., 89: 4907-4913.

Prentice, R.L., M.B. Pettinger, R.D. Jackson, J. Wactawski-Wende and A. Z. Lacroix et al., 2013. Health risks and benefits from calcium and vitamin D supplementation: Womens health initiative clinical trial and cohort study. Osteoporosis Intl., 24: 567-580.

Raghavan, R., F.S. Ashour and R. Bailey, 2016. A review of cutoffs for nutritional biomarkers. Adv. Nutr., 7: 112-120.

Rooney, M.R., L. Harnack, E.D. Michos, R.P. Ogilvie and C.T. Sempos et al., 2017. Trends in use of high-dose vitamin D supplements exceeding 1000 or 4000 international units daily, 1999-2014. J. Am. Med. Assoc., 317: 2448-2450.

Saldanha, L., J. Dwyer, K. Andrews, J. Betz and J. Harnly et al., 2015. Feasibility of including green tea products for an analytically verified dietary supplement database. J. Food Sci., 80: H883-H888.

Sander, L.C., M. Bedner, M.C. Tims, J.H. Yen and D.L. Duewer et al., 2012. Development and certification of green tea-containing standard reference materials. Anal. Bioanal. Chem., 402: 473-487.

Sebastian, R.S., C.W. Enns, J.D. Goldman and A.J. Moshfegh, 2017. Dietary flavonoid intake is inversely associated with cardiovascular disease risk as assessed by body mass index and waist circumference among adults in the United States. Nutrients, 9: 1-16.

Swanson, C.A., 2002. Suggested guidelines for articles about botanical dietary supplements. Am. J. clin. Nutr., 75: 8-10.

TGA., 2016. Australian government response to the review of medicines and medical devices regulation. Therapeutic Goods Administration, Australia. https:// www.tga.gov.au/australian-government-response-re view-medicines-and-medical-devices-regulation
TGA., 2018. Medicines and medical devices regulation review. Therapeutic Goods Administration, Australia. https://www.tga.gov.au/hubs/mmdr

Taylor, C.L. and E.A. Yetley, 2008. Nutrient risk assessment as a tool for providing scientific assessments to regulators. J. Nutr., 138: 1987S-1991S.

Taylor, C.L., 2004. Regulatory frameworks for functional foods and dietary supplements. Nutr. Rev., 62: 55-59.

Taylor, C.L., C.T. Sempos, C.D. Davis and P.M. Brannon, 2017. Vitamin D: Moving forward to address emerging science. Nutrients, 9: 1-15.

Taylor, C.L., R.L. Bailey and A.L. Carriquiry, 2015. Use of folate-based and other fortification scenarios illustrates different shifts for tails of the distribution of serum 25-hydroxyvitamin D concentrations. J. Nutr., 145: 1623-1626.

Trikalinos, T.A., J. Lee, D. Moorthy, W.W. Yu and J. Lau et al., 2012. Effects of Eicosapentanoic acid and docosahexanoic acid on mortality across diverse settings: Systematic review and meta-analysis of randomized trials and prospective cohorts. Master Thesis, Agency for Healthcare Research and Quality (AHRQ), North Bethesda, Maryland.

Tsai, H.H., H.W. Lin, A.S. Pickard, H.Y. Tsai and G.B. Mahady, 2012. Evaluation of documented drug interactions and contraindications associated with herbs and dietary supplements: A systematic literature review. Intl. J. Clin. Pract., 66: 1056-1078.

USFDA., 2018. Dietary supplements. US Food and Drug Administration, Maryland, USA. https://www.fda.gov/food/dietary-supplements

USFDA., 2018. New Dietary Ingredients (NDI) notification process. US Food and Drug Administration, Maryland, USA. https://www. fda.gov/food/dietary-supplements/new-dietary-ingr edients-ndi-notification-process

Ventola, C.L., 2010. Current issues regarding Complementary and Alternative Medicine (CAM) in the United States: Part 2: Regulatory and safety concerns and proposed governmental policy changes with respect to dietary supplements. P. T., 35: 514-522.

WHO., 2005. National policy on traditional medicine and regulation of herbal medicines-Report of a WHO global survey. World Health Organization, Geneva, Switzerland. http://apps.who. int/medicinedocs/en/d/Js7916e/

Wardenaar, F., N. Brinkmans, I. Ceelen, B.V. Rooij and M. Mensink et al., 2017. Micronutrient intakes in 553 Dutch elite and sub-elite athletes: Prevalence of low and high intakes in users and non-users of nutritional supplements. Nutrients, 9: 1-16. 
White, A., 1941. Growth-inhibition produced in rats by the oral administration of Sodium benzoate: Effects of various dietary supplements. Yale J. Boil. Med., 13: 759-768.

Wolsko, P.M., D.K. Solondz, R.S. Phillips, S.C. Schachter and D.M. Eisenberg, 2005. Lack of herbal supplement characterization in published randomized controlled trials. Am. J. Med., 118: 1087-1093.

World Health Organization, 2013. WHO Traditional Medicine Strategy: 2014-2023. World Health Organization, Geneva, Switzerland. ISBN:9789241506090, Pages: 76.
Yetley, E.A., 2007. Science in the Regulatory Setting: A Challenging but Incompatible Mix. In: Dietary Supplements and Health: Novartis Foundation Symposium, Bock, G. and J. Goode (Eds.). Novartis Foundation, Basel, Switzerland, ISBN:9780470034279, pp: 59-68.

Yetley, E.A., A.J. MacFarlane, L.S. Greene-Finestone, C. Garza and J.D. Ard et al., 2016. Options for basing Dietary Reference Intakes (DRIs) on chronic disease endpoints: Report from a joint US-/Canadian-sponsored working group. Am. J. Clin. Nutr., 105: 249S-285S. 